\title{
THE DYNAMICS OF STAGNATION: A PANEL ANALYSIS OF THE ONSET AND CONTINUATION OF STAGNATION
}

\author{
RichaRD BLUHM \\ Leibniz Universität Hannover \\ and \\ UNU-MERIT, Maastricht University \\ Denis de Crombrugghe \\ Maastricht University \\ ADAM SZIRMAI \\ UNU-MERIT, Maastricht University
}

This paper analyzes periods of economic stagnation in a panel of countries. We test whether stagnation can be predicted by institutional characteristics and political shocks and compare the impacts of such variables with those of traditional macroeconomic variables. We examine the determinants of stagnation episodes using dynamic linear and nonlinear models. In addition, we analyze whether the effects of the included variables on the onset of stagnation differ from their effects on the continuation of stagnation. We find that inflation, negative regime changes, real exchange rate undervaluation, financial openness, and trade openness have significant effects on both the onset and the continuation of stagnation. Only for trade openness is there robust evidence of a differential impact. Open economies have a significantly lower probability of falling into stagnation, but once in stagnation they do not recover faster.

Keywords: Growth Collapses, Stagnation, Institutions, Dynamic Panel Data

\section{INTRODUCTION}

Since the 1950s, many countries across the globe have experienced substantial increases in GDP per capita brought about by years of economic growth.

\footnotetext{
We gratefully acknowledge financial support from the Agence Française de Développement (AFD). This paper has benefited from comments, suggestions, and discussions with Nicholas Meisel, Bart Verspagen, Robin Cowan, Thomas Ziesemer, Kaj Thomsson, and the participants at the AFD "Institutions and Growth" workshop in Paris and similar workshops in Maastricht. The findings, interpretations, and conclusions expressed in this paper are solely the responsibility of the authors and do not necessarily represent policies or views of the UNU-MERIT, AFD, and/or other affiliated institutions. Address correspondence to: Richard Bluhm, Institute of Macroeconomics, Leibniz Universität Hannover, Königsworther Platz 1, 30167 Hannover, Germany; e-mail: bluhm@mak.uni-hannover.de.
} 
However, whereas these gains are mainly the result of steady positive growth rates in the developed world (at least prior to 2008), growth in developing countries has often been erratic and volatile. Most emerging economies have experienced periods of economic stagnation between positive growth spurts, and for several countries the absence of sustained growth has proved to be a persistent phenomenon, often lasting for several years or even decades. Explaining why some countries experience more periods of stagnation than others may thus prove essential to the understanding of contemporary differences in levels of development.

Rather than focusing on differences in average growth rates, recent research increasingly aims to unveil the specific characteristics of different growth episodes such as accelerated growth, growth collapses, recoveries, or stagnation. We address two questions within this wider research agenda. First, we ask whether institutional characteristics and external or internal political shocks determine the incidence of stagnation, and how these effects compare to standard macroeconomic explanations. Second, we analyze whether any of the included variables have a different impact on the onset of stagnation than on its continuation. In other words, we examine whether the factors affecting the probability of falling into stagnation are the same as those affecting the probability of continuing to be in stagnation.

Most of the empirical literature on growth episodes uses static models to study factors that are correlated with the onset of a growth spell and, more recently, is beginning to examine factors associated with the duration of growth episodes. Our contribution is to analyze stagnation spells as a dynamic problem, subject to state dependence and interactions between the lagged state and the independent variables. This approach allows the probability of stagnation to depend on whether a country was already in stagnation in the preceding year (state dependence). It lets the data decide whether the included variables have a different effect on the onset of a stagnation episode than on its continuation. We estimate the dynamic models using linear probability models, GMM, fixed-effects logit, and a dynamic random effects probit estimator proposed by Wooldridge (2005).

Our results indicate that political regime shifts toward autocracy have strong positive effects on the incidence of stagnation (onset and continuation), but other proxies for institutions and political shocks do not have significant effects. Macroeconomic factors explain the onset of stagnation rather well. Higher inflation positively predicts stagnation, whereas financial openness, trade openness, and real exchange rate undervaluation are associated with a reduced likelihood of stagnation. We find little evidence that the effects of these variables differ between the onset and continuation of stagnation spells. Only trade openness has robustly different effects. It substantially reduces the chances of falling into stagnation, but the "protective" effect of openness vanishes once a country is in a stagnation spell. In addition, we find that stagnation spells exhibit a moderate degree of state dependence, which is consistent with other results in the literature on the duration of growth collapses. 
The paper is organized as follows. Section 2 briefly reviews the literature on institutions and growth and discusses applications of the growth episodes approach. Section 3 defines stagnation episodes and explores their correlations with GDP levels and institutions. Section 4 describes the variables and data. Section 5 outlines the empirical strategy. Section 6 discusses the results. Section 7 concludes.

\section{RELATED LITERATURE}

An increasingly large body of literature in economics argues that differences in institutional characteristics are the key to understanding differences in the long-run economic performance of nations. Although modern institutional theory has many antecedents, it started from the hypothesis that one explanation for the historical rise of the West is well-developed property rights [e.g., North and Thomas (1973)]. Since the 1990s, this literature has been extended to view growth-promoting institutions less narrowly. More recent contributions argue, for example, that institutions for growth are multifaceted [Rodrik (2000)], interact with geography and inequality [Engerman and Sokoloff (1997)], develop semiendogenously [Greif (2006)], and are embedded in informal arrangements [North et al. (2009)]. ${ }^{1}$

In terms of econometric evidence, several papers have suggested that differences in institutions explain a large part-if not most—of the cross-country variation in level of GDP per capita. ${ }^{2}$ However, many of these studies have also been criticized for their underlying assumptions [e.g., Glaeser et al. (2004)] and do not generally establish a link between institutions and growth rates [Crombrugghe and Farla (2012)]. Potentially bridging this gap in theory, several authors have recently suggested that there is a link between institutional susceptibility to various external or internal shocks and different growth outcomes. North et al. (2009), for example, identify two distinct types of social orders. Open access orders are economically and politically highly developed, experience relatively smooth patterns of economic growth, and have active civil societies, many long-lived organizations, heavily formalized rules, and strong rule of law. Large segments of the population have access to political and economic organizations. Limited access orders, in contrast, are dominated by elites that exclude large parts of the population from access to economic and political organizations. The rents created in this process are then distributed among members of the ruling coalition in order to achieve a basic degree of social stability and control over violence. Limited access orders typically experience volatile growth patterns and are characterized by polities without broad democratic consent, few organizations, informal rules, weak and unequally enforced rule of law, insecure property rights, and high levels of inequality.

North et al. (2009) suggest that limited access orders are inflexible and less able to cope with shocks, thus causing a higher propensity to growth collapses and stagnation. Rodrik (1999) links negative growth experiences to terms-of-trade shocks, latent social conflict, and the ability of institutions to contain conflict and absorb the destructive potential of such shocks. A key question for this paper is to 
what extent an empirical analysis of stagnation episodes supports these theories. Therefore, we hypothesize that (a) institutional characteristics play an important role in explaining the onset of stagnation and (b) weak institutions prolong the incidence of stagnation spells.

As Pritchett (1998) pointed out, a problem in traditional panel studies of growth rates is that they focus on average trends over a fixed period, although in reality growth is often erratic and may be contingent on very different growth regimes. This conjecture gave birth to a rapidly growing literature, which since then has analyzed growth differentials across decades [Rodrik (1999)], growth accelerations [Hausmann et al. (2005)], switching among multiple growth regimes [Jerzmanowski (2006)], the duration of growth collapses [Hausmann et al. (2008)], start-and-stop growth [Jones and Olken (2008)], real income stagnation [Reddy and Minoiu (2009)], and the duration of growth accelerations [Berg et al. (2012)].

This paper relates most to the studies focusing on negative growth experiences. Rodrik (1999) provided the first evidence that growth collapses are linked to terms of trade shocks, latent conflict, and the conflict management capacity of institutions. Hausmann et al. (2008) examine the onset and duration of growth collapses. They mainly find that weak export performance and high inflation coincide with the onset of stagnation, but downturns also occur together with wars, sudden stops, and political transitions. However, most of these factors have little influence on the duration of collapses, which is only correlated with a measure of the flexibility of a country's export basket. Last, Reddy and Minoiu (2009) investigate the incidence of stagnation spells (periods of negative growth) and find that they are correlated with weak export performance, low investment, primary commodity exports, and weak institutions.

The study of stagnation spells and other negative growth episodes is also related to the business cycle literature and the literature on economic crises. Although the focus of this paper is primarily on longer-run growth episodes and not on short-run fluctuations, these literatures provide relevant insights and hypotheses [e.g., see Diebold et al. (1993) or duration dependence, Cerra and Saxena (2008) on post-crisis growth, and Bussière and Fratzscher (2006) on recession probabilities].

Most papers in the growth episodes literature use a methodology that can be summarized in two steps. First, a rule-based or statistical filter is applied to the data to identify single or multiple turning points in the GDP series. If the filter is rule-based, then it often includes a criterion implicitly or explicitly defining the length of the spell. If the filter is statistical, then it may find more than one break in the data and thus lead to the identification of distinct growth episodes. In the second step, correlates of these episodes are examined either by testing for differences in means of potentially correlated variables (before and during) or by estimating probit models. The unexamined assumption in these studies is that factors affecting the onset of an episode are the same as those determining whether an episode will continue. Further, most studies of growth episodes take very few measures to account for the possible endogeneity of the included regressors. 


\section{GROWTH EPISODES AND LONG-RUN GROWTH}

\subsection{Defining the Growth Episodes}

Our classification of growth episodes is a modification of the approach to growth collapses in Hausmann et al. (2008). We define a stagnation episode (or stagnation spell) as an event that begins with a contraction of GDP per capita at a time when it was higher than ever before, and ends when GDP per capita is again at or above its pre-stagnation level. We denote (for the purposes of this section) the log of GDP per capita in country $i$ in year $t$ by $Y_{i t}\left(i=1, \ldots, N ; t=1, \ldots, T_{i}\right)$. Defined formally, a stagnation episode begins when $Y_{i t}<Y_{i, t-1}$ and $Y_{i, t-1} \geq \max _{x=1}^{t-1} Y_{i, x}$, and lasts as long as $Y_{i, t+p}<Y_{i, t-1}(p=1,2, \ldots)$. When $Y_{i, t+p} \geq Y_{i, t-1}$, the stagnation spell is over. Conversely, we define all years when a country is not stagnating as expansion years. In other words, an expansion episode begins the first year a country has left (or when it has not yet experienced) a stagnation spell and lasts until the beginning of the next stagnation spell.

Apart from being very simple, these definitions have several desirable properties. A completed stagnation episode has a net effect of zero on the level of GDP per capita, because it includes both the downturn and the associated recovery. Conversely, the effect of an expansion episode on the level of GDP per capita is always positive. The definition of expansion explicitly excludes growth that is merely restoring what was lost in past crises, as this growth does not account for long-run increases in GDP per capita. Some commonly used filters, such as the Hausmann et al. (2005) growth accelerations filter, do not make this distinction between recoveries and expansions. Thus some of their growth accelerations include recoveries. [See also Bussière and Fratzscher (2006) on "post-crisis bias."]

An episode has a minimum duration of one year but can actually last for the entire length of the sampled period (1951-2007). Based on this definition, we can identify long stagnation episodes that may include recurring short-run recessions with incomplete recoveries-incomplete in the sense that the maximum level of GDP per capita prior to the crisis has not been recovered. Stagnation episodes thus designedly subsume many short-run business cycle fluctuations.

We further differentiate expansions and periods of stagnation into two subspells each. For stagnation episodes, we distinguish between crises, lasting from the beginning of the stagnation episode to the trough, and recoveries, lasting from the year after the trough until the end of the stagnation spell. We define the trough as occurring at the minimum level of output during a stagnation episode. For expansions, we distinguish between moderate expansions with an average growth rate up to 5\% per annum, and rapid expansions with an average growth rate surpassing 5\% per annum. ${ }^{3}$ In the rare case where growth in the first recovery year is so rapid that precrisis output is regained in one year, we consider that year part of an expansion, and exclude it from the stagnation spell.

We apply these definitions to GDP per capita data from the Penn World Table 6.3 [Heston et al. (2009)]. Excluding countries with less than one million inhabitants at the latest recorded year as well as countries with less than 20 years of data, we 

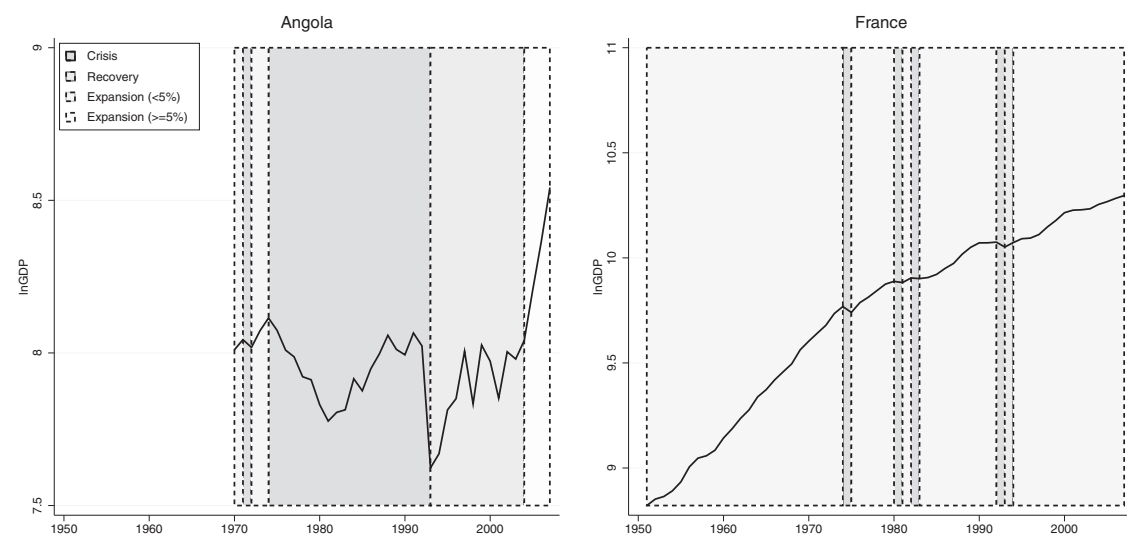

FIGURE 1. Examples of growth episodes: Angola and France.

observe 127 countries for a period of at least 20 years between 1950 and 2007. Within this sample, and hence before the beginning of the 2007 financial upheaval, we find a total of 578 stagnation episodes, or 3,276 country-years of stagnation.

Figure 1 illustrates how our filter works graphically as applied to Angola and France. These two examples are typical of the different growth experiences of developed and developing countries and show that the filter works reasonably well in identifying episodes of interest. Although Angola has had many years of positive growth throughout the sample period, we find only three short expansion spells, of which only the last is a rapid expansion. Instead, most of the time, Angola was in one protracted stagnation episode lasting from 1975 until the end of 2004, with significant volatility in between. In contrast, the French economy has grown steadily since 1951 and is characterized by protracted periods of moderate expansion, which are only temporarily interrupted by very short stagnation spells. In the light of these two stylized cases, we propose that the incidence of stagnation spells may explain a large part of the difference in long-run levels of GDP per capita.

\subsection{Growth Profiles}

Before focusing on the dynamics of moving into and out of stagnation spells, we first take a more detailed look at the distribution of growth episodes across countries and time. Do developing countries spend more of their time in crisis or stagnation than advanced economies? Are they more prone to experience crisis and stagnation? Using the previously defined growth episodes, Table 1 addresses these issues in more detail.

Table 1 groups the relative incidence of each type of growth episode from 1951 to 2007 by quartiles of GDP per capita in 2007. The table shows that 
TABLE 1. Growth episodes by income levels in 2007

\begin{tabular}{lccccr}
\hline \% Country-years in ... & Low & Low-mid & Mid-high & High & Total \\
\hline \multirow{5}{*}{ Panel A: Two episode types } \\
Expansion & 22.12 & 41.33 & 54.97 & 73.14 & 48.31 \\
Stagnation & 77.88 & 58.67 & 45.03 & 26.86 & 51.69 \\
& \multicolumn{5}{c}{ Panel B: Four episode types } \\
Expansion (above 5\%) & 10.21 & 11.52 & 23.18 & 22.66 & 16.99 \\
Expansion (5\% or less) & 11.91 & 29.81 & 31.79 & 50.49 & 31.32 \\
Crisis & 49.90 & 30.63 & 23.81 & 17.42 & 30.18 \\
Recovery & 27.98 & 28.04 & 21.22 & 9.44 & 21.51 \\
\hline
\end{tabular}

Notes: Number of countries 127, number of observations 6,338, percentages calculated over 1951 to 2007.

low-income countries spend most of their time in stagnation, upper middle-income countries almost half the time, and high-income countries only about a quarter. This suggests that the different propensity to experience stagnation spells is closely linked to development outcomes today. Further, using the finer classification of four distinct growth episode types - crisis, recovery, expansion, rapid expansionwe find that a large proportion of time spent in crises at low and lower-middle income levels is driving this relationship. Once we exclude recoveries from the positive growth experiences, there is little indication that lower-income countries experience rapid growth more frequently than higher-income countries during expansions (as unconditional convergence would imply). In fact, the opposite seems to be the case. Although countries in the lowest income group spend relatively more of their expansions growing rapidly $(10.21 / 22.12 \approx 46.15 \%)$, upper-middle-income and high-income countries spend more time growing rapidly in total. Table 1 confirms that currently poor countries have experienced fewer years of positive growth than rich countries. This contradicts the assertion that when poor countries grow, they do so more rapidly than the rich. ${ }^{4}$

As mentioned earlier, North et al. (2009) suggest lasting institutional differences between limited access orders and open access orders as one possible explanation for the lack of generalized convergence among economies. Developing countries with limited access orders are less adaptive, less able to adjust to various external and internal shocks, and more prone to economic crises and stagnation.

Table 2 links the conjecture of North et al. (2009) and similar theories to the approach developed in this paper by cross-tabulating the different growth episodes with two indices of institutional characteristics; institutional formalization of regulations and degree of control and intervention by the state. These indices are derived from Crombrugghe and Farla (2012), who aggregate a large number of indicators from the Institutional Profiles Database (IPD) 2009 using principal components analysis. ${ }^{5}$ Similarly to the income classification used before, we group the scores on each component into quartiles ranked from low to high. The upper panel in 
TABLE 2. Growth episodes by institutional indicators

\begin{tabular}{lrccrr}
\hline \% Country-years in ... & Low & Low-mid & Mid-high & High & Total \\
\hline & & Panel A: Formalization of regulations & \\
Expansion & 30.49 & 40.92 & 54.61 & 76.41 & 51.06 \\
Stagnation & 69.51 & 59.08 & 45.39 & 23.59 & 48.94 \\
Total & 100.00 & 100.00 & 100.00 & 100.00 & 100.00 \\
Expansion (above 5\%) & 14.49 & 16.15 & 20.86 & 18.38 & 17.47 \\
Expansion (5\% or less) & 16.00 & 24.78 & 33.75 & 58.03 & 33.60 \\
Crisis & 40.29 & 37.13 & 21.80 & 14.51 & 28.29 \\
Recovery & 29.22 & 21.95 & 23.59 & 9.08 & 20.65 \\
& & Panel B: Control and intervention & \\
Expansion & 54.98 & 68.17 & 50.56 & 30.55 & 51.06 \\
Stagnation & 45.02 & 31.83 & 49.44 & 69.45 & 48.94 \\
Total & 100.00 & 100.00 & 100.00 & 100.00 & 100.00 \\
Expansion (above 5\%) & 25.36 & 13.77 & 20.68 & 11.67 & 17.47 \\
Expansion (5\% or less) & 29.62 & 54.40 & 29.87 & 18.88 & 33.60 \\
Crisis & 26.81 & 18.13 & 28.39 & 39.96 & 28.29 \\
Recovery & 18.21 & 13.70 & 21.05 & 29.49 & 20.65 \\
\hline
\end{tabular}

Notes: Number of countries 47 in 1951, 107 in 2007; total number of observations 5,405 (Panels A and B); percentages calculated on the basis of all years between 1951 and 2007.

Table 2 shows the results for the first component and the lower panel the results for the second.

There is a moderately strong negative correlation (about -0.5 for 2007 ) between the index of institutional formalization of regulations and the incidence of stagnation episodes. The countries belonging to the highest quartile on this index are in stagnation less than $25 \%$ of the sample period, whereas those ranked in the lowest quartile stagnate almost $70 \%$ of the time. In many ways these results resemble those using income groups. For example, fast expansions occur more frequently in the upper middle quartile and crises occur gradually less often at higher quartiles of the index. This suggests that higher institutional formalization of regulations is associated with fewer stagnation spells and increasingly steady growth. However, there is a strong correlation (about 0.8) between GDP per capita and the formalization index, so the direction of causality remains indeterminate.

The bottom panel of Table 2 gives a more differentiated picture. The second principal component, which can be interpreted as the degree of the state's involvement in the private economy but also as its degree of authoritarianism, is associated with more frequent stagnation spells. The lowest incidence of stagnation spells $(31.83 \%)$ occurs within the group of countries scoring in the lower middle quartile of the index, whereas countries in the highest quartile stagnated during nearly $70 \%$ 
of the sample period. As Crombrugghe and Farla (2012, p. 17) point out, "Western European countries, the USA, Canada, and Australia are at neither extreme of the [index]," which suggests that very low scores represent weak states and very high scores represent mostly authoritarian regimes. This explains why the most stable growth profile is located in the lower middle quartile rather than at either end of the spectrum.

This brief overview of different growth episodes between 1950 and 2007 highlights two points. First, the incidence of stagnation spells is much higher in lowerand middle-income countries than in high-income countries. Second, weak institutions and especially a lack of formalized rules and regulations could be driving less steady growth and more frequent stagnation, but this aspect requires further analysis.

\section{EXPLANATORY VARIABLES}

In the preceding section, we have reported how we defined and obtained our sample of stagnation spells and examined their distribution. In this section, before we start modeling the incidence of stagnation, we briefly outline the sources for and construction of explanatory variables. These broadly belong to two categories: macroeconomic indicators and variables describing political institutions as well as external or internal shocks to these institutions. Table A.1 in the Appendix provides an overview.

Macroeconomic variables. We include a range of variables that are typically associated with sound macroeconomic management. Most of these variables have been found to significantly affect growth performance in traditional panel studies using annual, quinquennial (5-year), or decennial (10-year) growth rates.

To control for the level of development, we include the lagged log of GDP per capita $\left(\log \mathrm{GDPC}_{(\mathrm{t}-1)}\right)$ in nearly all models. Its expected effect is negative, considering that richer countries tend to experience fewer and shorter stagnation spells. Controlling for the level of GDP also serves a practical purpose. As indicated in the previous section, indices measuring the quality of institutions and GDP are strongly correlated, so that including both will avoid erroneously attributing effects of one to the other.

Maintaining price stability is a core task of central banks and its importance is emphasized in the related literature [e.g., Berg et al. (2012)]. We expect high inflation to be positively correlated with the onset of stagnation spells. However, for continuation of stagnation, the role of inflation is likely to be ambiguous, as it could be instrumental-together with the exchange rate-in bringing about devaluation and regaining competitiveness. Our measure of inflation is 100 times the $\log$ of 1 plus the annual inflation rate. This measure is close to the actual inflation rate when that rate is low, but also reduces the influence of larger values 
(e.g., rare periods of hyperinflation). The annual inflation data are from the IMF's International Financial Statistics (IFS), complemented with data from the World Development Indicators (WDI) whenever the former are missing.

We also measure whether the exchange rate is overvalued or undervalued in real terms. Recent research finds that depreciations are beneficial for growth accelerations [Hausmann et al. (2005)] and stimulate growth in general [Rodrik (2008)]. This positive effect may operate through many channels, but is most commonly linked to export-led growth and the relative price of manufactured products. On the negative side, abrupt movements of the exchange rate can also be an omen of excessive volatility and an upcoming currency crisis. If the positive consequences are dominant, exchange rate undervaluation may diminish the likelihood of stagnation spells. To capture this effect, we follow Rodrik (2008) in constructing an index of exchange rate undervaluation (RER Value $(\mathrm{t}-1)) .{ }^{6}$ The index is centered at zero, with higher values indicating exchange rate undervaluation and lower values indicating overvaluation.

We include two measures of trade performance. First, we measure the price of exports relative to imports, the terms of trade $\left(\Delta \operatorname{ToT}_{(\mathrm{t}-1)}\right)$, as the annual log difference of the net barter terms of trade from the WDI, and supplement this series with data from the IFS when there are gaps in the WDI series. Terms of trade growth, declines, and shocks have been linked to growth collapses [Rodrik (1999); Hausmann et al. (2008)], accelerations [Hausmann et al. (2005)], and the premature end of fast growth spells [Berg et al. (2012)]. Second, we also estimate the effects of changes in the value of real merchandise exports $\left(\Delta\right.$ Real Exports $\left._{(\mathrm{t}-1)}\right)$, which we measure as the annual log difference of the exports volume index from the WDI, appended with data from the IFS to extend coverage. Growth in real exports has been found to reduce the probability of the onset of a stagnation spell significantly [Hausmann et al. (2008)]. We examine whether this is also the case in the presence of dynamics.

Further, the growth literature has identified de jure financial and trade openness as two key policy variables that positively influence growth outcomes. To account for the former, we include the Chinn and Ito (2006) index of financial openness (Fin. Openness ${ }_{(t-1)}$ ). This index is the first principal component of the inverses of four variables measuring restrictions on external accounts, based on the IMF's Annual Report on Exchange Arrangements and Exchange Restrictions (AREAER). To account for the latter, we use a dummy measure for economic liberalization (Trade Openness ${ }_{(\mathrm{t}-1)}$ ) developed by Sachs and Warner (1995) and extended by Wacziarg and Welch (2008). This indicator is coded as one in years when a given country is completely open to trade and zero otherwise. Although the index's authors have linked their respective measures to average growth rates, the growth episodes literature has found financial openness to precede growth accelerations [Hausmann et al. (2005)] and trade liberalization to reduce the risk of a fast growth spell ending [Berg et al. (2012)]. Financial liberalization can lead to both increasing capital inflows and financial deepening, but also enable capital flight and generally volatile capital flows. The sign of its effect is not clear ex ante. 
In contrast, we expect trade openness to unequivocally reduce the probability of stagnation.

Last, we include a measure for income inequality after taxes and transfers (Inequality $\left._{(t-1)}\right)$. Net income inequality is not only an economic variable but just as much influenced by a country's political institutions. Most of the growth episodes literature does not systematically analyze the role of inequality, with the exception of an early study by Rodrik (1999) and recent evidence of a negative effect on the length of positive growth spells [Berg et al. (2012)]. In panel studies the effect of inequality on average growth rates remains disputed. ${ }^{7}$ However, parts of neo-institutional theory [Engerman and Sokoloff (1997)] and earlier work on the interaction of inequality and growth collapses [Rodrik (1999)] suggest a negative sign for inequality, whereas earlier theories suggests that inequality rises alongside rapid development and falls again at higher income levels [Kuznets (1955)]. Our data for net income inequality are taken from Solt (2009), who appends, benchmarks, and standardizes data from UNU-WIDER's World Income Inequality Database (WIID).

Institutional and "shock" variables. This set of variables aim to capture some observable cross-country heterogeneity that can be attributed to institutions, as well as various shocks that require a response from policy makers and economic actors within the constraints of the political and institutional structure. These shocks may be external or internal but have in common that they pose a challenge to the prevailing regime and/or a country's institutional set-up.

Cross-sectional studies of GDP levels find strong support for the conclusion that institutions explain large parts of long-run growth [Knack and Keefer (1995); Hall and Jones (1999); Acemoglu et al. (2001, 2002)] and also provide evidence that growth-enhancing institutions (e.g., property rights or executive constraints) contribute to lower growth volatility [Acemoglu et al. (2003)]. We expect that more open and democratically constrained institutions ${ }^{8}$ will reduce the probability of experiencing a stagnation spell. Our measure of political institutions is the revised combined polity score Polity $_{(\mathrm{t}-1)}$ ) from the Polity IV project (Marshall and Jaggers, 2010). This measure is the difference between a country's score on the aggregate institutionalized democracy index and the score on the institutionalized autocracy index coded by the Polity IV project. It has a range from -10 (hereditary monarchy) to +10 (consolidated democracy). For studies requiring time series, the Polity IV data are uniquely suitable, as they provide annual data, starting as early as 1800 .

From Polity IV, we also derive two additional measures of political shocks. We code a dummy for positive regime changes (Regchange $\left.+_{(t-1)}\right)$ as major positive changes of the political structure identified by at least a three-point improvement in the polity score. Conversely, we code negative regime changes (Regchange $\left.-_{(t-1)}\right)$ as a negative change of at least three points in the polity score, including interregna and state failure. We expect negative regime changes to increase the probability of stagnation, whereas positive regime changes may have a stagnation 
deferring effect. Regime transitions in general may also be a sign of political instability or consolidation of power.

We also include a dummy for the irregular exit of leaders (Leader Exit $_{(\mathrm{t}-1)}$ ) based on Archigos 2.9 [Goemans et al. (2009)] as a proxy for internal shocks to a country's political regime. This variable codes an irregular exit whenever a country's major leader (president, chancellor, dictator, and so forth) loses power by means that violate established rules and conventions. Such cases include, but are not limited to, the loss of power due to removal by foreign intervention, assassinations, ill health, and domestic popular protest with foreign support. We focus on leader exit and not entry, as our aim is to link periods of stagnation to unexpected adverse events and not to their possible resolution. Some studies of growth accelerations have accounted for the sudden death of leaders in office but usually not other types of exit [Hausmann et al. (2005); Jones and Olken (2008)].

In order to investigate the impact of large scale violence on stagnation spells, we include a dummy for the occurrence of War/Conflict $\mathrm{t}_{\mathrm{t}-1)}$ based on the UCDP/PRIO Armed Conflict Dataset v.4-2011 [Gleditsch et al. (2002)]. We expect countries that are the locations of interstate war or large civil strife to be especially prone to falling into stagnation spells. Our measure codes a war if UCDP/PRIO records a conflict intensity of two or higher, corresponding to at least 1,000 battlerelated deaths in a country-year, and if the country is recorded as a location of war. In the case of multiple conflicts, we select the conflict with the highest intensity.

\section{EMPIRICAL STRATEGY}

Most extant studies of growth episodes use pooled probit or nonlinear panel methods to study the onset of specific growth episodes, such as accelerations or collapses. We know of only two papers concerned with modeling the duration of growth spells using observations within the episode [Hausmann et al. (2008); Berg et al. (2012)]. Other studies exploit only part of the data, either retaining only the first observations of the episodes of interest, or comparing averages of covariates before and after a regime change [e.g., Jones and Olken (2008)]. However, we are unaware of any theoretical justification for assuming that determinants of stagnation explain only its onset and not its continuation. Apart from the obvious loss of efficiency, the neglect of information from within episodes also brings with it the risk of rare event bias [King and Zeng (2001)].

In fact, state dependence is likely be a crucial feature of growth episodes in general and of stagnation spells in particular. Yet, apart from Jerzmanowski's (2006) Markov-switching models, the literature does not model the incidence of a growth spell as a dynamic process. The likely explanation is that, in dynamic nonlinear models, special efforts are required to address econometric issues such as spurious state dependence, endogeneity of the lagged state, unobserved heterogeneity, the initial conditions problem, and nonlinear interaction effects.

We propose to phase the issues and first introduce dynamics into a generic linear model of stagnation episodes. This generic model will be used for an initial 
screening and selection of potential explanatory variables. The linear estimates will also be used to provide initial variance estimates for more complex nonlinear models. Ultimately, linear estimates remain interesting, as they are much less demanding in terms of statistical assumptions than the potentially more efficient nonlinear models, and they provide robust benchmark estimates.

For ease of exposition, we write the general model in index form, leaving the functional form unspecified:

$$
\begin{aligned}
y_{i t} & =\mathbf{1}\left[\alpha y_{i, t-1}+\mathbf{x}_{i t}^{\prime} \boldsymbol{\beta}+\mathbf{x}_{i t}^{\prime} y_{i, t-1} \gamma+\mu_{i}+v_{i t}>0\right], \\
i & =1, \ldots, N, \quad t=2, \ldots, T_{i},
\end{aligned}
$$

where $y_{i t}$ indicates whether or not a country $i$ is stagnating in year $t, y_{i, t-1}$ is the lagged state, $\mathbf{x}_{i t}$ is a vector of covariates, $\boldsymbol{\alpha}, \boldsymbol{\beta}$ and $\boldsymbol{\gamma}$ are parameters to be estimated, $\mu_{i}$ is a time-invariant unobserved country effect, and $\nu_{i t}$ is a residual time-varying error. The interaction term $\left(\mathbf{x}_{i t}^{\prime} y_{i, t-1} \gamma\right)$ allows the impact of the covariates to be different in (or just after) a stagnation spell than in expansions. For now, the unobserved effects may be of the "fixed" or "random" variety: nothing is assumed about their distribution or the absence of correlation with the explanatory variables. In most specifications, we will also include quinquennial dummies among the regressors, though not their interactions with $y_{i, t-1}$.

In the linear case, the elements of the parameter vector $\gamma$ can be interpreted as slope shifts in the effects of the variables in $\mathbf{x}_{i t}$ if a country is or has just been in a stagnation spell (i.e., $y_{i, t-1}=1$ ), whereas mean shifts are captured by $\alpha$. This model allows us to test the hypothesis that specific elements or subsets of $\gamma$ are equal to zero. Macroeconomics and political economy provide little guidance as to whether and how some effects should differ in the initial and later stages of a stagnation episode. Our modeling strategy is to "let the data decide" which variables in $\mathbf{x}_{i t}$ require an interaction term with $y_{i, t-1}$ and which do not. We proceed in four steps. First, we estimate fully interacted linear probability models specified according to equation (1). Second, we test whether the interaction terms that are individually insignificant at the $10 \%$ level may also be considered jointly insignificant. Third, based on these tests, we specify a "parsimonious" reference model retaining only those interactions that pass our inclusion criteria. Fourth, we compare the preceding results with those found using nonlinear probability models.

\subsection{Linear Probability Models}

Simplest of all is to estimate equation (1) as a linear probability model (LPM) with country fixed effects (FE). This approach is particularly attractive, as FEOLS requires no distributional assumptions about the unobserved effects and the OLS coefficients are usually a good approximation to the partial effects near the means of the variables. However, the variance of the dependent variable is known to be of the form $\mathbf{x}_{i t}^{\prime} \boldsymbol{\beta}\left(1-\mathbf{x}_{i t}^{\prime} \boldsymbol{\beta}\right)$, making the LPM inherently heteroskedastic. 
Furthermore, the LPM can predict probabilities outside the unit interval and hence nonpositive variances, unless the predictions are arbitrarily trimmed.

In model (1), the LPM has two further shortcomings. First, it implies awkward restrictions on the unobserved effects. Second, because the same unobserved effects $\left(\mu_{i}\right)$ also appear in the lagged state $y_{i, t-1}$, their presence means that the "Within" OLS estimate of $\alpha$ is downward biased [Nickell (1981)]. The Nickell bias is decreasing in $T$. Our panel has an average length of about 18 years; therefore the bias should be moderate.

For comparison, we also estimate equation (1) using differenced and system generalized methods of moments (GMM) estimators. Differenced GMM uses lagged levels of order two and higher as instruments for the endogenous regressors in a differenced equation [Holtz-Eakin et al. (1988); Arellano and Bond (1991)]. To alleviate problems of weak instrumentation, Arellano and Bover (1995) and Blundell and Bond (1998) proposed a "system GMM" estimator that instruments levels with lagged differences and estimates the equation both in differences and in levels simultaneously. Under the appropriate conditions, system GMM is consistent and more efficient than differenced GMM. The extra moment conditions require that the lagged differences not be correlated with the unobserved effects. In addition, system GMM requires that the initial conditions $\left(y_{i 1}\right)$ represent a stationary equilibrium, which is arguably an unnatural assumption for the analysis of stagnation spells. We apply two-step system GMM with a small sample correction due to Windmeijer (2005).

System GMM is not a universal panacea. Bun and Windmeijer (2010) recently showed that the level equation in system GMM also suffers from a weak instruments problem. Differenced or system GMM estimates are also often unstable and strongly depend on the instrument matrix used [Roodman (2009)]. For this reason, we do not use GMM for model selection but only apply it to the "parsimonious" specification to check whether the results remain within a reasonable range of the FE-OLS estimates.

\subsection{Nonlinear Probability Models}

Simple within or first-difference transformations cannot eliminate unobserved heterogeneity in nonlinear probability models such as logit and probit models, and the assumptions made on the structure of the unobserved effects determine which types of model can be estimated. We apply two techniques: fixed-effects logit and dynamic random-effects probit. On one hand, the fixed-effects logit estimator is less restrictive in its assumptions about the unobserved heterogeneity, but similarly to the LPM with FE, it does not deal with the endogeneity of the lagged state. On the other hand, the dynamic random effects probit estimator requires explicit assumptions about the unobserved heterogeneity, but has been modified to account for the endogeneity of the lagged state, including solutions for the initial conditions problem. 
Fixed-effects logit. The dummy variables fixed-effects logit model estimated by unconditional maximum likelihood (ML) runs into a statistical problem. Even in a simplified version of equation (1) without the lagged state, we need a consistent estimate over $t=1, \ldots, T_{i}$ for each of the unobserved effects $\mu_{i}$. Any inconsistency introduced there will contaminate the estimate of $\boldsymbol{\beta}$. This is the well-known incidental parameters problem, which, for balanced panels, creates a bias in the ML estimator of $\boldsymbol{\beta}$ on the order of $1 / T$ [Neyman and Scott (1948)]. Given the lengths of our series, we do not expect the bias to be large.

Chamberlain (1980) observed that there is a computational trick that allows consistent estimation of the parameter vector but not the constants by conditioning on the sum of observed outcomes within groups $\left(\sum_{t=1}^{T_{i}} y_{i t}\right)$. In the conditional logit model the incidental parameters $\left(\mu_{i}\right)$ drop out. However, conditioning on the sum of the observed outcomes comes at a cost. Because groups in which $y_{i t}$ does not change over $T_{i}$ provide no information on the likelihood, they drop out of the log-likelihood. If there is strong persistence, the number of observations used in the estimation may fall a lot. Likewise, time-invariant effects cancel out of the estimation equation. They cannot be estimated, nor can partial effects, because these depend on the expected value of the unobserved effects.

Given the expectation that the unconditional ML estimator is not too strongly biased and allows estimation of partial effects, we estimate both models and compare their results.

Dynamic random effects probit. Conditioning on the sum of the observed outcomes does not work for the equivalent probit model. Furthermore, the standard random effects probit model assumes that the unobserved heterogeneity is strictly unrelated to the explanatory variables. The presence of the lagged state $\left(y_{i, t-1}\right)$ together with $\mu_{i}$ violates this assumption even if $\alpha$ is actually zero [Wooldridge (2010, p. 626)]. This is the problem of true versus spurious state dependence. The estimated effect of $y_{i, t-1}$ depends on three sources: (1) serial correlation in the errors, (2) correlation with the unobserved effects, and (3) true state dependence [Greene (2011, p. 769)]. In such a setting, the ordinary fixed or random effects estimation techniques do not provide consistent estimates. In addition, the outcome path may be strongly influenced by the initial conditions $\left(y_{i 1}\right)$, which enter the unconditional likelihood function and prohibit integrating out the unobserved effects $\left(\mu_{i}\right)$. We are faced with two related problems: the violation of strict exogeneity in the presence of unobserved heterogeneity, and the treatment of the initial condition in the log-likelihood.

A relaxation of the strict exogeneity assumption known as correlated random effects has been developed for static models following the ideas of Mundlak (1978) and Chamberlain (1984). The approach allows for correlation between $\mathbf{x}_{i t}$ and $\mu_{i}$ but restricts the unobserved effects to depend on means (or other values) of the explanatory variables according to $\mu_{i}=\eta_{0}+\overline{\mathbf{x}}_{i}^{\prime} \boldsymbol{\eta}_{2}+\varepsilon_{i}$, where the $\varepsilon_{i}$ are assumed to be i.i.d. and normally distributed. The vector $\overline{\mathbf{x}}_{i}$ consists of time averages (or other values, such as initial levels) of the regressors $\mathbf{x}_{i t} \cdot{ }^{9}$ Although this approach 
relaxes the strict exogeneity assumption, it does not address the issue of dynamics and the related initial conditions problem.

Several solutions to the initial conditions problem have been proposed [see Heckman (1981); Orme (2001); Wooldridge (2005)]. Wooldridge (2005) suggests conditioning the density $\left(y_{i 1}, \ldots, y_{i T_{i}}\right)$ on the observed history of the covariates and the initial values by specifying a distribution of the unobserved effects given the initial conditions. Rabe-Hesketh and Skrondal (2013) show that this simple method performs well in general and Akay (2012) provides Monte Carlo evidence that a constrained model (with time averages) also works well in unbalanced panels as long the time series lengths are moderately large.

Concretely, Wooldridge (2005) proposes to condition on the entire time series of the strictly exogenous variables less the initial period plus the initial condition $\left(y_{i 1}\right)$ - an approach that extends easily to interactions. A convenient way to specify the conditional distribution of the unobserved effects is $\mu_{i} \mid y_{i 1}, \overline{\mathbf{x}}_{i} \sim \mathcal{N}\left(\eta_{0}+\eta_{1} y_{i 1}+\overline{\mathbf{x}}_{i}^{\prime} \boldsymbol{\eta}_{2}+\overline{\mathbf{x}}_{i}^{\prime} y_{i 1} \boldsymbol{\eta}_{3}, \sigma_{\varepsilon}^{2}\right)$, where $\overline{\mathbf{x}}_{i}$ are the time averages as in Mundlak-Chamberlain. This implies the following parametric specification for the unobserved effects: $\mu_{i}=\eta_{0}+\eta_{1} y_{i 1}+\overline{\mathbf{x}}_{i}^{\prime} \boldsymbol{\eta}_{2}+\overline{\mathbf{x}}_{i}^{\prime} y_{i 1} \boldsymbol{\eta}_{3}+\varepsilon_{i}$, where the $\varepsilon_{i}$ are normal, i.i.d., and independent of $\left(y_{i 1}, \overline{\mathbf{x}}_{i}\right)$.

As a final model, we specify the constrained probit version of equation (1):

$$
\begin{gathered}
P\left(y_{i t}=1 \mid \mathbf{x}_{i 2}, \ldots, \mathbf{x}_{i T_{i}}, y_{i, t-1}, \ldots, y_{i 1}, \varepsilon_{i}\right) \\
=\Phi\left(\alpha y_{i, t-1}+\mathbf{x}_{i t}^{\prime} \boldsymbol{\beta}+\mathbf{x}_{i t}^{\prime} y_{i, t-1} \gamma+\eta_{0}+\eta_{1} y_{i 1}+\overline{\mathbf{x}}_{i}^{\prime} \boldsymbol{\eta}_{2}+\overline{\mathbf{x}}_{i}^{\prime} y_{i 1} \boldsymbol{\eta}_{3}+\varepsilon_{i}\right)
\end{gathered}
$$

where $\mathbf{x}_{i t}$ is the vector of explanatory variables, $y_{i, t-1}$ is the lagged state, $\overline{\mathbf{x}}_{i}$ is the vector of time averages of the covariates, the vector $\gamma$ allows for differential effects of the covariates depending on the state $\left(\mathbf{x}_{i t} y_{i, t-1}\right), \eta_{1}$ measures the effect of the initial condition $\left(y_{i 1}\right)$, and the vector $\boldsymbol{\eta}_{3}$ measures the effect of the averaged covariates depending on the initial condition $\left(\overline{\mathbf{x}}_{i} y_{i 1}\right)$. Estimation still proceeds over $i=1, \ldots, N$ and $t=2, \ldots, T_{i}$.

Appendix B outlines why the average partial effects (APEs), which are not identified in the conditional logit model, are in fact identified in this random effects probit model. This model addresses all three fundamental issues in our research problem. It specifies a data-coherent functional form, relaxes the strict exogeneity assumption, and consistently estimates the APE of time-varying variables and the lagged state variable in the presence of unobserved effects.

Partial effects of interactions. It is well known that the partial effects in nonlinear models are not constant and that the model coefficients indicate only the direction and approximate significance of the effects. A somewhat less well known fact is that nonlinearity necessarily implies that the coefficients of the interaction terms do not represent the sign, size, or significance of the underlying interaction effect [e.g., see Ai and Norton (2003); Greene (2010)]. Let $F\left(\mathbf{w}_{i t} ; \boldsymbol{\theta}\right)=$ $F\left(\alpha y_{i, t-1}+\mathbf{x}_{i t}^{\prime} \boldsymbol{\beta}+\mathbf{x}_{i t}^{\prime} y_{i, t-1} \gamma+\mu_{i}\right)$ denote a generic nonlinear version of our interaction model with an implicit error, and let circumflexes indicate estimated 
values. The change in the partial effect of $x_{k, i t} \in \mathbf{x}_{i t}$ due to a regime switch into stagnation $\left(\Delta y_{i, t-1}=1\right)$ is

$$
\operatorname{PE}\left(\hat{\gamma}_{k}\right)_{i t}=\Delta F_{k}^{\prime}\left(\mathbf{w}_{i t} ; \hat{\boldsymbol{\theta}}\right)=F_{k}^{\prime}\left(\mathbf{w}_{i t} ; \hat{\boldsymbol{\theta}} \mid y_{i, t-1}=1\right)-F_{k}^{\prime}\left(\mathbf{w}_{i t} ; \hat{\boldsymbol{\theta}} \mid y_{i, t-1}=0\right),
$$

where $F_{k}^{\prime}\left(\mathbf{w}_{i t} ; \hat{\boldsymbol{\theta}}\right)$ can denote either a partial derivative with respect to $x_{k, i t}$ or a difference, depending on whether $x_{k, i t}$ is discrete or continuous, and in either case we write $F_{k}^{\prime}\left(\mathbf{w}_{i t} ; \hat{\boldsymbol{\theta}}\right)=\partial F\left(\mathbf{w}_{i t} ; \hat{\boldsymbol{\theta}}\right) / \partial x_{k, i t}$.

Clearly, $\hat{\gamma}_{k}$ is not equal to the interaction effect as it would be in a linear model. Now it is straightforward to compute the APE for either $\Delta y_{i, t-1}=1$ or $\Delta y_{i, t-1}=-1$ as

$$
\operatorname{APE}\left(\hat{\gamma}_{k}\right)=\frac{1}{N(\bar{T}-1)} \sum_{i=1}^{N} \sum_{t=2}^{T_{i}} \frac{\Delta F^{\prime}\left(\mathbf{w}_{i t} ; \hat{\boldsymbol{\theta}}\right)}{\Delta y_{i, t-1}},
$$

where $\bar{T}$ is the average panel size.

We compute the standard errors of the APEs using the delta method, so that the asymptotic variance of the APE of an interaction with the lagged state is

$$
\widehat{\operatorname{AVar}}\left[A P E\left(\hat{\gamma}_{k}\right)\right]=\frac{\partial \operatorname{APE}\left(\hat{\gamma}_{k}\right)}{\partial \hat{\boldsymbol{\theta}}^{\prime}} \widehat{\Omega} \frac{\partial \operatorname{APE}\left(\hat{\gamma}_{k}\right)}{\partial \hat{\boldsymbol{\theta}}},
$$

and $\widehat{\Omega}$ is the ML estimate of the asymptotic covariance matrix of $\hat{\boldsymbol{\theta}}$. For the observation-specific partial effects, the Jacobian vectors are not averaged.

\section{RESULTS AND DISCUSSION}

\subsection{Linear Models}

Table 3 reports the results from variations of the LPM. Because we primarily use the linear models for variable selection, we only briefly discuss the results and defer the economic interpretation until the description of the preferred specification in the next subsection. Column (1) is the standard fixed-effects model with standard errors clustered at the country level. Column (2) is similar but allows for arbitrary heteroskedasticity and autocorrelation within both country and time clusters [Cameron et al. (2011)]. Column (3) shows the FGLS estimator with clustering at the country level via the weights. Column (4) is the parsimonious FGLS specification discarding those interaction terms that are individually and jointly insignificant. Columns (5) and (6) reestimate (4) using system GMM.

Two joint hypothesis tests reported in Table 3 are key to our model-building approach. First, we test whether the coefficients of the interactions with the lagged state and the coefficient of the lagged state are jointly zero; taken together these variables compose Set I. In all models this hypothesis is rejected, indicating the presence of dynamics. Second, we test whether the interactions with the lagged state that are individually insignificant at the $10 \%$ level (i.e., Set II) can also 
TABLE 3. Linear models: Probability of stagnation

\begin{tabular}{|c|c|c|c|c|c|c|c|c|c|c|c|c|}
\hline Independent variable & $\begin{array}{c}(1) \\
\text { LPM }\end{array}$ & S.E. & $\begin{array}{c}(2) \\
\text { LPM }\end{array}$ & S.E. & $\begin{array}{c}(3) \\
\text { FGLS }\end{array}$ & S.E. & $\begin{array}{c}(4) \\
\text { FGLS }\end{array}$ & S.E. & $\begin{array}{c}(5) \\
\text { SYS-GMM }\end{array}$ & S.E. & $\begin{array}{c}(6) \\
\text { SYS-GMM }\end{array}$ & S.E. \\
\hline $\log \mathrm{GDPC}_{(t-1)}$ & 0.052 & 0.073 & 0.052 & 0.094 & 0.061 & 0.073 & 0.040 & 0.065 & -0.018 & 0.035 & -0.029 & 0.020 \\
\hline Inflation $_{(t-1)}$ & $0.005^{*}$ & 0.003 & 0.005 & 0.004 & $0.005^{* *}$ & 0.002 & $0.005^{* *}$ & 0.002 & 0.003 & 0.004 & 0.013 & 0.010 \\
\hline$\Delta \operatorname{ToT}_{(t-1)}$ & -0.080 & 0.081 & -0.080 & 0.082 & -0.092 & 0.109 & -0.036 & 0.054 & -0.035 & 0.043 & -0.056 & 0.049 \\
\hline$\Delta$ Real Exports $(t-1)$ & -0.136 & 0.169 & -0.136 & 0.177 & -0.080 & 0.143 & -0.014 & 0.047 & 0.011 & 0.067 & 0.055 & 0.062 \\
\hline $\operatorname{RER}_{\operatorname{Value}_{(t-1)}}$ & $-0.150^{*}$ & 0.088 & -0.150 & 0.113 & -0.083 & 0.075 & -0.016 & 0.039 & $-0.146^{* * *}$ & 0.046 & $-0.155^{* * *}$ & 0.042 \\
\hline Fin. Openness $(t-1)$ & $-0.043^{* * *}$ & 0.016 & $-0.043^{* *}$ & 0.020 & $-0.042^{* *}$ & 0.017 & $-0.034^{* *}$ & 0.016 & $-0.043^{*}$ & 0.023 & -0.020 & 0.026 \\
\hline Trade Openness $_{(t-1)}$ & $-0.236^{* * *}$ & 0.081 & $-0.236^{* * *}$ & 0.073 & $-0.233^{* * *}$ & 0.062 & $-0.231^{* * *}$ & 0.058 & -0.185 & 0.148 & $-0.286^{* *}$ & 0.125 \\
\hline Inequality $_{(t-1)}$ & -0.007 & 0.004 & -0.007 & 0.005 & -0.003 & 0.004 & -0.002 & 0.003 & $0.007^{* *}$ & 0.003 & $0.005^{* *}$ & 0.002 \\
\hline Polity $2_{(t-1)}$ & -0.011 & 0.007 & -0.011 & 0.007 & $-0.008^{*}$ & 0.005 & -0.003 & 0.003 & -0.003 & 0.004 & -0.004 & 0.004 \\
\hline Regchange $+_{(t-1)}$ & 0.033 & 0.068 & 0.033 & 0.077 & 0.006 & 0.103 & 0.017 & 0.032 & 0.036 & 0.036 & 0.031 & 0.043 \\
\hline Regchange $-{ }_{(t-1)}$ & $0.338^{*}$ & 0.187 & 0.338 & 0.202 & $0.277^{*}$ & 0.149 & $0.274^{*}$ & 0.143 & 0.450 & 1.050 & $0.348^{*}$ & 0.210 \\
\hline Leader Exit $_{(t-1)}$ & -0.071 & 0.053 & -0.071 & 0.055 & -0.045 & 0.054 & 0.004 & 0.028 & -0.037 & 0.043 & -0.033 & 0.043 \\
\hline $\log \operatorname{GDPC}_{(t-1)} \times y_{(t-1)}$ & 0.002 & 0.048 & 0.002 & 0.050 & -0.039 & 0.042 & & & & & & \\
\hline Inflation $_{(t-1)} \times y_{(t-1)}$ & $-0.004^{*}$ & 0.003 & -0.004 & 0.004 & $-0.005^{* *}$ & 0.002 & $-0.005^{* *}$ & 0.002 & -0.002 & 0.004 & -0.012 & 0.010 \\
\hline$\Delta \operatorname{ToT}_{(t-1)} \times y_{(t-1)}$ & 0.031 & 0.093 & 0.031 & 0.084 & 0.067 & 0.125 & & & & & & \\
\hline$\Delta$ Real Exports $(t-1) \times y_{(t-1)}$ & 0.117 & 0.166 & 0.117 & 0.169 & 0.073 & 0.151 & & & & & & \\
\hline $\operatorname{RER~Value}_{(t-1)} \times y_{(t-1)}$ & 0.146 & 0.103 & 0.146 & 0.105 & 0.081 & 0.075 & & & & & & \\
\hline
\end{tabular}




\begin{tabular}{|c|c|c|c|c|c|c|c|c|c|c|c|c|}
\hline Independent variable & $\begin{array}{c}(1) \\
\text { LPM }\end{array}$ & S.E. & $\begin{array}{c}(2) \\
\text { LPM }\end{array}$ & S.E. & $\begin{array}{c}(3) \\
\text { FGLS }\end{array}$ & S.E. & $\begin{array}{c}(4) \\
\text { FGLS }\end{array}$ & S.E. & $\begin{array}{c}(5) \\
\text { SYS-GMM }\end{array}$ & S.E. & $\begin{array}{c}\text { (6) } \\
\text { SYS-GMM }\end{array}$ & S.E. \\
\hline Fin. Openness $s_{(t-1)} \times y_{(t-1)}$ & 0.021 & 0.019 & 0.021 & 0.019 & $0.034^{*}$ & 0.018 & 0.023 & 0.016 & $0.064^{* *}$ & 0.029 & 0.038 & 0.039 \\
\hline Trade Openness $_{(t-1)} \times y_{(t-1)}$ & $0.186^{* *}$ & 0.084 & $0.186^{* *}$ & 0.088 & $0.207^{* * *}$ & 0.066 & $0.208^{* * *}$ & 0.059 & 0.132 & 0.169 & $0.292^{*}$ & 0.148 \\
\hline Inequality $_{(t-1)} \times y_{(t-1)}$ & 0.001 & 0.003 & 0.001 & 0.004 & 0.001 & 0.003 & & & & & & \\
\hline Polity $2_{(t-1)} \times y_{(t-1)}$ & 0.007 & 0.007 & 0.007 & 0.007 & 0.007 & 0.005 & & & & & & \\
\hline Regchange $+_{(t-1)} \times y_{(t-1)}$ & -0.017 & 0.068 & -0.017 & 0.076 & 0.011 & 0.108 & & & & & & \\
\hline Regchange $-{ }_{(t-1)} \times y_{(t-1)}$ & $-0.354^{*}$ & 0.184 & $-0.354^{*}$ & 0.193 & $-0.280^{*}$ & 0.166 & $-0.277^{*}$ & 0.160 & -0.399 & 1.040 & $-0.363^{*}$ & 0.211 \\
\hline 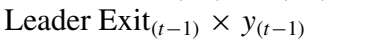 & $0.101^{*}$ & 0.060 & 0.101 & 0.068 & 0.059 & 0.060 & & & & & & \\
\hline War/Conflict $_{(t-1)} \times y_{(t-1)}$ & $-0.171^{* *}$ & 0.081 & $-0.171^{*}$ & 0.090 & -0.126 & 0.096 & & & & & & \\
\hline$y_{(t-1)}$ & 0.158 & 0.473 & 0.158 & 0.505 & 0.486 & 0.423 & $0.222^{* * *}$ & 0.059 & $0.363^{* *}$ & 0.160 & $0.317^{* *}$ & 0.141 \\
\hline Constant & 0.758 & 0.746 & 0.373 & 0.846 & 0.463 & 0.647 & 0.617 & 0.560 & 0.368 & 0.392 & $0.508^{*}$ & 0.261 \\
\hline Observations & 1691 & & 1691 & & 1691 & & 1691 & & 1691 & & 1691 & \\
\hline Country FE & Yes & & Yes & & Yes & & Yes & & - & & - & \\
\hline Clusters & Country & & Country+year & & Country & & Country & & Country & & Country & \\
\hline Joint: Country FE [ $p$-values] & 0.000 & & 0.000 & & 0.000 & & 0.000 & & & & & \\
\hline Joint: 5-Year FE [ $p$-values] & 0.101 & & 0.451 & & 0.430 & & 0.364 & & 0.053 & & 0.024 & \\
\hline Joint: Set I [ $p$-values] & 0.000 & & 0.000 & & 0.000 & & 0.000 & & 0.000 & & 0.000 & \\
\hline Joint: Set II [ $p$-values] & 0.796 & & 0.226 & & 0.708 & & 0.167 & & 0.759 & & 0.038 & \\
\hline Instruments & & & & & & & & & 390 & & 35 & \\
\hline AR1 [ $p$-value] & & & & & & & & & 0.000 & & 0.000 & \\
\hline AR2 [ $p$-value $]$ & & & & & & & & & 0.304 & & 0.120 & \\
\hline Hansen's $J$ [ $p$-value] & & & & & & & & & 1.000 & & 0.327 & \\
\hline
\end{tabular}


be jointly omitted. In columns (1) to (4), the insignificant interactions pass this joint-exclusion test, but not in the GMM estimates.

All fully interacted specifications provide very similar results. Inflation, financial openness, trade openness, and negative regime changes clearly affect the probability of entering a stagnation spell. Considering the interactions, the coefficients of inflation, trade openness, and negative regime changes are significant in most but not all specifications. Interestingly, the interaction terms often have the opposite sign of the noninteracted coefficients, indicating that the respective effects are weaker within a stagnation spell. Column (4) only retains the significant interactions and represents our parsimonious specification, which we later reestimate with nonlinear techniques. We still find evidence that inflation, trade openness, and negative regime changes have a different impact within the spell than on the onset probabilities. However, the interaction effect of financial openness is, again, insignificant.

The system GMM specifications in columns (5) and (6) assess the stability of the parameter estimates once we account for the endogeneity of the lagged state and the interactions with the lagged state. Although the significance of individual coefficients changes between the two GMM models, the sizes and signs of the previously highlighted coefficients remain broadly similar. In column (5) we use the second and third lag of the predetermined variables as instruments. Nevertheless, the $J$-test indicates that the number of instruments is too large relative to the group size. We address this concern in column (6) by collapsing the instrument set [see Roodman (2009)]. There is no evidence of instrument endogeneity, and the estimated parameters come closer to the earlier least-squares estimates. However, applying GMM in our context is not ideal. A moderate $\bar{T}$ quickly leads to instrument proliferation and problems in identifying an instrument set that balances efficiency gains with decreasing relevance. Accordingly, we place less emphasis on the GMM results and rely more on verifying the results from the preceding linear models with nonlinear techniques.

The linear models point to several preliminary conclusions. First, we find that inflation, financial openness, trade openness, and negative regime changes have a statistically significant effect on the probability of stagnation, and so to a lesser extent do exchange rate undervaluation and inequality. Second, state dependence plays a large role in determining whether a country experiences a stagnation episode or not. Third, in all specifications there is considerable evidence of unobserved heterogeneity at the country level. Fourth, all significant interaction terms with the lagged state point in the direction opposite to their linear counterparts.

\subsection{Nonlinear Models}

Turning to the nonlinear models, we first discuss the heterogeneity of the interaction effects using a logit specification and then present the results from the dynamic random effects probit estimator (our preferred specification). 
Table 4 shows the estimation results from two types of fixed-effects logit estimators. As a reference, column (1) shows the fully interacted model estimated using conditional maximum likelihood, where the fixed effects are not estimated but drop out. Column (2) is the conditional logit equivalent of the parsimonious linear model, and column (3a) is the same model using dummy variables for the country fixed effects. The last column (3b) reports the APEs based on column (3a). The APEs of interaction terms are reported similarly to coefficients of a linear model; that is, if $y_{i, t-1}=0$, the APE is reported in the row of the noninteracted variable and, for $y_{i, t-1}=1$, the total APE is the sum of the former and the APE of the interaction term.

A complication in interpreting the results of the conditional logit models is that the APEs are not identified, for the simple reason that the individual country effects are not estimated. To approximate the APEs, we estimate the equivalent dummy variable fixed-effects logit model and compute the APEs based on its results. Columns (2) and (3a) show that the parameter estimates and the corresponding standard errors remain very similar, justifying this approach.

We still find evidence that inflation, financial openness, trade liberalization, and negative regime changes significantly affect the probability of stagnation. However, for all but negative regime changes, the APEs of the interaction terms are statistically insignificant and in the case of financial openness the interaction effect no longer points in the opposite direction. Applying fixed-effects logit also substantially reduces the estimation sample to 1,314 observations in 62 countries, for lack of within-group variation. This loss of observations makes it impossible to identify the effect of the negative regime change interaction term; as a consequence, the interaction is dropped from the earlier parsimonious model.

The APEs are close to the linear approximation in terms of size. Notable changes are that now the effects of changes in the terms of trade, real exchange rate (RER) undervaluation, and inequality are all significant at the $10 \%$ level and have increased substantially in absolute size. The degree of state dependence identified by the logit model is also somewhat higher than in the linear approximation (32.1 percentage points higher probability of continuation if a country was stagnating the year before).

Table 4 may seem to provide little evidence that some variables have a different impact on the onset of a stagnation spell than on its continuation. However, in nonlinear models, the partial effects of the interaction can be very heterogeneous at the observation level and may be individually significant for a substantial subset of observations. By definition, APEs average out this type of heterogeneity, which can be especially troublesome if the partial effects switch signs. In Figure 2 we examine these nonlinearities more closely. The figure graphs the distributions of partial effects for the interaction terms of inflation, financial openness, and trade openness over the predicted probability of stagnation, as well as the associated $p$-values of a Wald test of the null that the interaction effect at each particular observation is zero. 
TABLE 4. Logit models: Probability of stagnation

\begin{tabular}{|c|c|c|c|c|c|c|c|c|}
\hline Independent variable & $\begin{array}{c}(1) \\
\text { Logit CML }\end{array}$ & S.E. & $\begin{array}{c}(2) \\
\text { Logit CML }\end{array}$ & S.E. & $\begin{array}{c}(3 a) \\
\text { Logit ML }\end{array}$ & S.E. & $\begin{array}{c}(3 b) \\
\text { APEs }\end{array}$ & S.E. \\
\hline $\log \mathrm{GDPC}_{(t-1)}$ & 0.417 & 0.707 & 0.430 & 0.695 & 0.430 & 0.738 & 0.058 & 0.099 \\
\hline $\operatorname{Inflation}_{(t-1)}$ & 0.037 & 0.025 & 0.043 & 0.026 & 0.046 & 0.028 & $0.006^{*}$ & 0.004 \\
\hline$\Delta \operatorname{ToT}_{(t-1)}$ & -0.556 & 0.571 & $-0.828^{*}$ & 0.479 & $-0.885^{*}$ & 0.516 & $-0.119^{*}$ & 0.070 \\
\hline$\Delta$ Real Exports $(t-1)$ & -0.784 & 1.163 & -0.621 & 0.735 & -0.681 & 0.795 & -0.091 & 0.107 \\
\hline $\operatorname{RER~Value}_{(t-1)}$ & $-1.375^{* *}$ & 0.567 & $-0.957^{*}$ & 0.503 & $-1.020^{*}$ & 0.533 & $-0.137^{*}$ & 0.071 \\
\hline Fin. Openness $(t-1)$ & $-0.453^{* * *}$ & 0.121 & $-0.396^{* * *}$ & 0.110 & $-0.421^{* * *}$ & 0.118 & $-0.058^{* * *}$ & 0.016 \\
\hline Trade Openness $_{(t-1)}$ & $-1.441^{* * *}$ & 0.486 & $-1.424^{* * *}$ & 0.456 & $-1.527^{* * *}$ & 0.489 & $-0.259^{* * *}$ & 0.091 \\
\hline Inequality $_{(t-1)}$ & -0.050 & 0.031 & $-0.052^{*}$ & 0.029 & $-0.054^{*}$ & 0.030 & $-0.007^{*}$ & 0.004 \\
\hline Polity $2_{(t-1)}$ & -0.066 & 0.044 & -0.051 & 0.033 & -0.054 & 0.036 & -0.007 & 0.005 \\
\hline Regchange $+_{(t-1)}$ & 0.193 & 0.561 & 0.129 & 0.376 & 0.136 & 0.397 & 0.018 & 0.054 \\
\hline Regchange $-{ }_{(t-1)}$ & $2.102^{* *}$ & 0.900 & $1.945^{* *}$ & 0.938 & $2.038^{* *}$ & 0.991 & $0.288^{* *}$ & 0.135 \\
\hline Leader $\operatorname{Exit}_{(t-1)}$ & -0.501 & 0.426 & -0.060 & 0.317 & -0.058 & 0.334 & -0.007 & 0.044 \\
\hline War/Conflict $_{(t-1)}$ & 0.115 & 0.382 & -0.428 & 0.342 & -0.454 & 0.357 & -0.059 & 0.045 \\
\hline $\log \operatorname{GDPC}_{(t-1)} \times y_{(t-1)}$ & 0.082 & 0.284 & & & & & & \\
\hline Inflation $_{(t-1)} \times y_{(t-1)}$ & -0.012 & 0.012 & -0.019 & 0.015 & -0.021 & 0.016 & -0.002 & 0.002 \\
\hline$\Delta \operatorname{ToT}_{(t-1)} \times y_{(t-1)}$ & -1.128 & 1.025 & & & & & & \\
\hline$\Delta$ Real Exports $(t-1) \times y_{(t-1)}$ & 0.290 & 1.244 & & & & & & \\
\hline
\end{tabular}


TABLE 4. Continued

\begin{tabular}{|c|c|c|c|c|c|c|c|c|}
\hline Independent variable & $\begin{array}{c}(1) \\
\text { Logit CML }\end{array}$ & S.E. & $\begin{array}{c}\text { (2) } \\
\text { Logit CML }\end{array}$ & S.E. & $\begin{array}{c}(3 a) \\
\text { Logit ML }\end{array}$ & S.E. & $\begin{array}{l}(3 b) \\
\text { APEs }\end{array}$ & S.E. \\
\hline $\operatorname{RER~Value~}_{(t-1)} \times y_{(t-1)}$ & 0.859 & 0.624 & & & & & & \\
\hline Fin. Openness ${ }_{(t-1)} \times y_{(t-1)}$ & 0.144 & 0.117 & 0.045 & 0.107 & 0.045 & 0.116 & -0.011 & 0.022 \\
\hline Trade Openness $_{(t-1)} \times y_{(t-1)}$ & $0.947^{*}$ & 0.528 & $0.885^{*}$ & 0.487 & $0.939^{*}$ & 0.521 & 0.153 & 0.094 \\
\hline Inequality $_{(t-1)} \times y_{(t-1)}$ & 0.003 & 0.019 & & & & & & \\
\hline Polity $_{(t-1)} \times y_{(t-1)}$ & 0.013 & 0.042 & & & & & & \\
\hline Regchange $+_{(t-1)} \times y_{(t-1)}$ & -0.164 & 0.620 & & & & & & \\
\hline 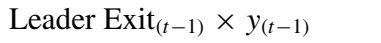 & $0.833^{*}$ & 0.506 & & & & & & \\
\hline War/Conflict $_{(t-1)} \times y_{(t-1)}$ & $-1.051^{*}$ & 0.537 & & & & & & \\
\hline$y_{(t-1)}$ & -0.004 & 2.813 & $1.189^{* * *}$ & 0.456 & $1.282^{* * *}$ & 0.487 & $0.321^{* * *}$ & 0.029 \\
\hline Observations & 1314 & & 1314 & & 1314 & & & \\
\hline Country FE & Yes & & Yes & & Yes & & & \\
\hline 5-year FE & Yes & & Yes & & Yes & & & \\
\hline Clustered errors [Country] & Yes & & Yes & & Yes & & & \\
\hline Countries & 62 & & 62 & & 62 & & & \\
\hline Log-pseudolikelihood & -465.864 & & -469.311 & & -555.547 & & & \\
\hline
\end{tabular}

Notes: In column (1), Regchange $-_{(t-1)} \times y_{(t-1)}$ was dropped because of a lack of within-group variance. The asymptotic standard errors of the APEs are computed via the delta method.

${ }^{* * *} p<0.01 ;{ }^{* *} p<0.05 ;{ }^{*} p<0.1$. 

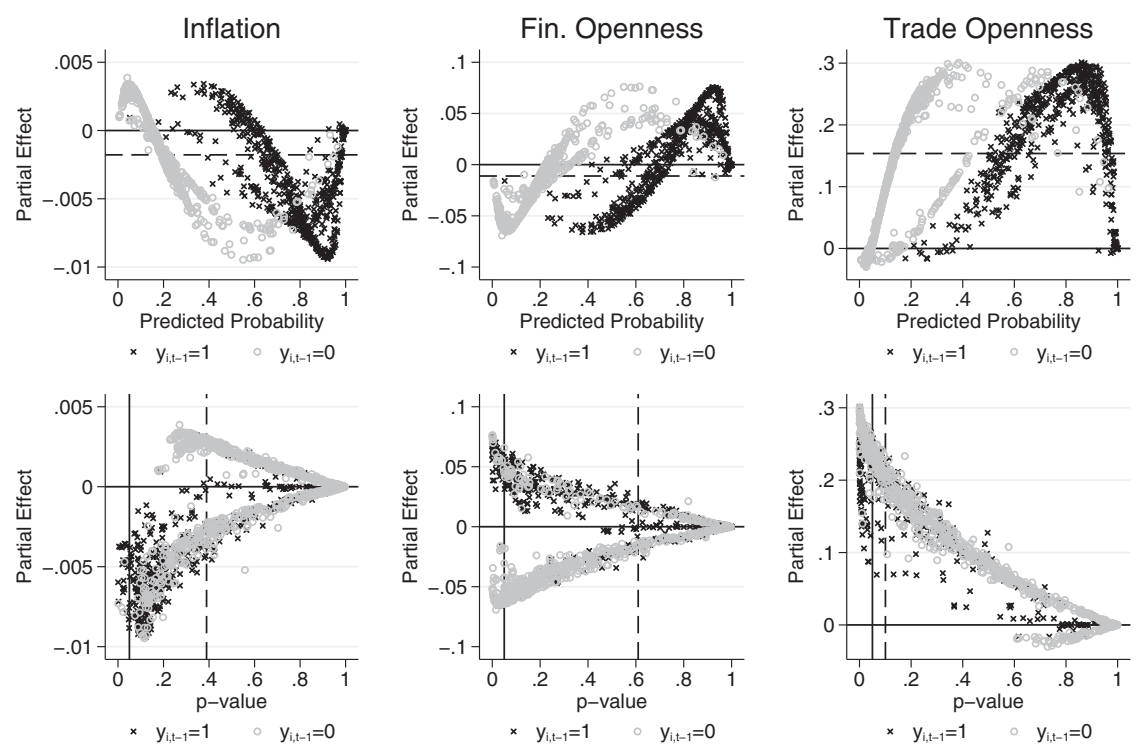

FIGURE 2. Partial effects of interaction terms in logit model. The dashed line refers to the APE in the upper panel and the $p$-value of a Wald test that the APE is zero in the lower panel."Predicted probability" is the probability of stagnation, $P\left(y_{i t}=1\right)$.

Clearly, the partial effects of all three interaction terms are extremely nonlinear and tend to include both positive and negative values. In the case of inflation, we find that for some observations the partial effect is positive, but for most observations it is negative and insignificant. The effect is significant only at negative values for a very small fraction of the distribution (30 observations) and ranges from $-0.95 \%$ to $0.39 \%$, which is moderately large compared to an APE of $0.6 \%$ when $y_{i, t-1}=0$. The predicted partial effects group into two families of curves with an S-shape. The curves at lower stagnation probabilities are the partial effects for observations where $y_{i, t-1}=0$ (symbol: o) and the curves going across higher stagnation probabilities are the predicted effects for observations where $y_{i, t-1}=1$ (symbol: $\mathrm{x}$ ). The dashed line refers to the APE in the upper panel and the $p$-value of a Wald test that the APE is zero in the lower panel.

The interaction effect for financial openness is also S-shaped but slopes upward and ranges from $-6.9 \%$ to $7.6 \%$. The partial effect is statistically significant for $14 \%$ of the predicted outcomes at both negative and positive values. However, similarly to inflation, the large range of insignificant negative and positive values supports the conclusion that the effect is not different from zero on the average. In contrast, the evidence of a significant interaction is relatively strong for trade openness. For most observations, the partial effect of the interaction term is positive and very large, with an overall range from $-3 \%$ to $30 \%$. For about $32 \%$ of the 
observations in the sample, the partial effect of the interaction term is individually significant at the $5 \%$ level.

Overall, the logit specifications confirm the findings of the linear models, given a few refinements. Inflation, financial openness, trade openness, and negative regime changes remain significant predictors of being in stagnation. Further, the estimates suggest that exchange rate undervaluation, changes in the terms of trade, and inequality affect the probability of stagnation. However, the evidence in favor of interaction effects with the lagged state for any variable other than trade openness is weak; the estimates suggest that only trade openness has a different impact on the onset of a stagnation spell than its continuation.

We now turn to the last and final set of estimates. Table 5 presents the random effects probit estimates of the dynamic panel model. For comparison purposes, we first report the naïve pooled probit version of the fully interacted dynamic model and then its random effects counterpart estimated according to the Wooldridge approach-columns (1) and (2), respectively. Column (3a) is the parsimonious version of the dynamic random effects model in column (2) and our preferred specification. Column (3b) reports the APEs of the variables of interest and their associated standard errors.

We report several additional rows in Table 5 to display the regression results more succinctly. The row " $\eta_{2}$-estimated?" refers to whether the MundlakChamberlain time averages are included. As these are not interesting by themselves, we do not report their coefficients and partial effects. Similarly, the row " $\eta_{3}$-estimated?" reports whether the interaction terms are included twice, once as an interaction with the lagged state and once as an interaction with the initial condition. We also do not report the parameter estimates of the latter, as they primarily account for the nonrandom nature of the unobserved effects.

The random effects probit model gives different (and superior) estimates compared to the pooled probit version. ${ }^{10}$ Several parameters exhibit sign changes and substantial changes in significance levels. More interestingly, even though the Wooldridge estimator of the dynamic model includes several additional terms and requires the assumption that the regressors are only correlated with the unobserved heterogeneity through their averages, the results are remarkably similar to those of the linear models (in Table 3) and logit specifications (in Table 4). We are not able to compute the partial effects at the observation level, as only the APEs across the entire distribution of the unobserved heterogeneity are identified [see Appendix B and Wooldridge (2005)].

The APE of inflation is similar to that in the previous models. According to the Wooldridge estimator, a unit increase in the inflation index in $t-1$ translates into 0.5 percentage points higher probability of stagnation in year $t$, if the country was not in stagnation in $t-1$. The APE of the interaction effect is $-0.3 \%$ and insignificant at all conventional levels, supporting the view that inflation increases the chances of stagnation, no matter if this occurs within or outside of a stagnation spell. We find no evidence in favor of the hypothesis that (higher) inflation helps exit a stagnation spell. 
TABLE 5. Probit models: Probability of stagnation

\begin{tabular}{|c|c|c|c|c|c|c|c|c|}
\hline Independent variable & $\begin{array}{c}(1) \\
\text { Probit }\end{array}$ & S.E. & $\begin{array}{c}(2) \\
\text { Woold }\end{array}$ & S.E. & $\begin{array}{c}(3 a) \\
\text { Woold }\end{array}$ & S.E. & $\begin{array}{c}(3 \mathrm{~b}) \\
\text { APEs }\end{array}$ & S.E. \\
\hline $\log \operatorname{GDPC}_{(t-1)}$ & 0.027 & 0.103 & 0.449 & 0.377 & 0.398 & 0.367 & 0.083 & 0.076 \\
\hline $\operatorname{Inflation}_{(t-1)}$ & $0.017^{* * *}$ & 0.006 & 0.012 & 0.008 & $0.020^{* * * *}$ & 0.008 & $0.005^{* * *}$ & 0.002 \\
\hline$\Delta \operatorname{ToT}_{(t-1)}$ & -0.328 & 0.300 & -0.435 & 0.476 & -0.321 & 0.349 & -0.067 & 0.072 \\
\hline$\Delta$ Real Exports $_{(t-1)}$ & -0.226 & 0.540 & -0.570 & 0.565 & -0.362 & 0.358 & -0.075 & 0.074 \\
\hline $\operatorname{RER}_{\text {Value }}(t-1)$ & $-0.719^{* * *}$ & 0.202 & $-0.786^{* *}$ & 0.331 & $-0.513^{*}$ & 0.278 & $-0.106^{*}$ & 0.058 \\
\hline Fin. Openness $_{(t-1)}$ & -0.056 & 0.039 & $-0.205^{* * *}$ & 0.074 & $-0.153^{* *}$ & 0.073 & $-0.038^{* *}$ & 0.018 \\
\hline Trade Openness $_{(t-1)}$ & $-0.567^{* * *}$ & 0.217 & $-0.926^{* * *}$ & 0.240 & $-0.774^{* * *}$ & 0.228 & $-0.218^{* * *}$ & 0.068 \\
\hline Inequality $_{(t-1)}$ & $0.014^{* *}$ & 0.007 & -0.026 & 0.016 & -0.022 & 0.015 & -0.004 & 0.003 \\
\hline Polity $2_{(t-1)}$ & -0.014 & 0.013 & -0.031 & 0.020 & $-0.027^{*}$ & 0.016 & $-0.006^{*}$ & 0.003 \\
\hline Regchange $+{ }_{(t-1)}$ & 0.039 & 0.269 & 0.138 & 0.405 & 0.066 & 0.220 & 0.014 & 0.046 \\
\hline Regchange $-{ }_{(t-1)}$ & $1.074^{*}$ & 0.557 & $1.238^{* *}$ & 0.617 & $1.047^{*}$ & 0.584 & $0.214^{*}$ & 0.112 \\
\hline Leader $\operatorname{Exit}_{(t-1)}$ & -0.196 & 0.188 & -0.118 & 0.235 & -0.006 & 0.171 & -0.001 & 0.035 \\
\hline War/Conflict $_{(t-1)}$ & 0.110 & 0.257 & 0.280 & 0.374 & -0.199 & 0.246 & -0.041 & 0.051 \\
\hline $\log \operatorname{GDPC}_{(t-1)} \times y_{(t-1)}$ & -0.259 & 0.182 & -0.129 & 0.154 & & & & \\
\hline Inflation $_{(t-1)} \times y_{(t-1)}$ & -0.008 & 0.006 & -0.004 & 0.008 & -0.012 & 0.008 & -0.003 & 0.002 \\
\hline$\Delta \operatorname{ToT}_{(t-1)} \times y_{(t-1)}$ & -0.091 & 0.393 & -0.097 & 0.750 & & & & \\
\hline$\Delta$ Real Exports $\operatorname{Ex}_{(t-1)} \times y_{(t-1)}$ & -0.435 & 0.574 & 0.286 & 0.745 & & & & \\
\hline
\end{tabular}


TABLE 5. Continued

\begin{tabular}{|c|c|c|c|c|c|c|c|c|}
\hline Independent variable & $\begin{array}{c}(1) \\
\text { Probit }\end{array}$ & S.E. & $\begin{array}{c}(2) \\
\text { Woold }\end{array}$ & S.E. & $\begin{array}{c}(3 a) \\
\text { Woold }\end{array}$ & S.E. & $\begin{array}{l}(3 \mathrm{~b}) \\
\text { APEs }\end{array}$ & S.E. \\
\hline $\operatorname{RER}_{\text {Value }}^{(t-1)} \times y_{(t-1)}$ & 0.635 & 0.390 & $0.532^{*}$ & 0.308 & & & & \\
\hline Fin. Openness $(t-1) \times y_{(t-1)}$ & 0.096 & 0.060 & 0.086 & 0.078 & -0.019 & 0.068 & -0.006 & 0.017 \\
\hline 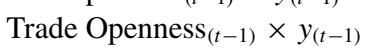 & 0.474 & 0.321 & $0.816^{* * *}$ & 0.262 & $0.646^{* * *}$ & 0.238 & $0.186^{* * *}$ & 0.067 \\
\hline Inequality $_{(t-1)} \times y_{(t-1)}$ & 0.005 & 0.012 & 0.008 & 0.011 & & & & \\
\hline Polity $2_{(t-1)} \times y_{(t-1)}$ & 0.008 & 0.022 & 0.005 & 0.020 & & & & \\
\hline Regchange $+_{(t-1)} \times y_{(t-1)}$ & 0.166 & 0.284 & -0.137 & 0.482 & & & & \\
\hline Leader $\operatorname{Exit}_{(t-1)} \times y_{(t-1)}$ & 0.290 & 0.259 & 0.201 & 0.290 & & & & \\
\hline War/Conflict $_{(t-1)} \times y_{(t-1)}$ & -0.267 & 0.404 & $-0.803^{*}$ & 0.458 & & & & \\
\hline$y_{0}$ & & & 0.969 & 2.621 & $1.244^{* * *}$ & 0.477 & & \\
\hline$y_{(t-1)}$ & $3.407^{*}$ & 1.787 & 1.554 & 1.569 & $1.020^{* * *}$ & 0.229 & $0.389^{* * *}$ & 0.035 \\
\hline Constant & -1.287 & 1.105 & -0.733 & 2.482 & -2.958 & 1.871 & & \\
\hline Observations & 1586 & & 1471 & & 1596 & & & \\
\hline $\boldsymbol{\eta}_{2}$-estimated? & NO & & YES & & YES & & & \\
\hline $\boldsymbol{\eta}_{3}$-estimated? & NO & & YES & & YES & & & \\
\hline 5-year FE & YES & & YES & & YES & & & \\
\hline Countries & 90 & & 81 & & 90 & & & \\
\hline Pseudo- $R^{2}$ & 0.423 & & 0.269 & & 0.255 & & & \\
\hline Log likelihood & -632.218 & & -574.211 & & -596.272 & & & \\
\hline
\end{tabular}

Notes: In column (1) Regchange $-(t-1) \times y_{(t-1)}$ was dropped because of a lack of within-group variance. The asymptotic standard errors of the APEs are computed via the delta method.

${ }^{* * *} p<0.01 ;{ }^{* *} p<0.05 ;{ }^{*} p<0.1$ 
Next, the effect of financial openness is also similar to that estimated by the linear probability model. A unit increase in the Chinn-Ito index toward more openness reduces the probability of stagnation by 3.8 percentage points. The APE of the interaction term is small and insignificant $(-0.6 \%)$, suggesting that there is no difference between onset and continuation probabilities. This result is particularly interesting, because capital account openness is sometimes restricted during crises to avert capital flight. Yet we find no evidence that it increases the risk of stagnation when a country is already stagnating, but instead it seems to be associated with a lower probability of crisis throughout.

In the case of trade openness, a discrete change toward openness when $y_{i, t-1}=0$ has an average partial effect of $-21.8 \%$, which is similar to the previous results. The interaction term is highly significant and has a very large effect on the predicted probability of stagnation (18.6\%). Adding these two effects, we get the APE for the probability of continued stagnation if $y_{i, t-1}=1$ and the country is open to trade, which is still negative but statistically insignificant $(-3.2 \%)$. Trade openness has already been shown to affect growth rates [Wacziarg and Welch (2008)], growth accelerations [Hausmann et al. (2005)], and the duration of positive growth spells [Berg et al. (2012)]. Our results add that open economies are significantly less likely to fall into stagnation spells - this is the single largest effect of a nonpolitical variable in all specifications - but also that openness does not significantly improve the chances of exiting a stagnation spell.

This finding suggests that, on top of typically being linked to higher average growth rates, trade openness is "good for growth" in the sense that it protects countries from stagnation. Although trade benefits growth through specialization, technological diffusion, and higher investment levels, it can also stabilize and accelerate growth, but it does not necessarily lead to shorter crises (especially when these are caused by international factors). Arguably, the weaker withinstagnation effect could also be driven by the fact that countries often liberalize in response to an ongoing crisis, which often yields no immediate benefits and can temporarily increase volatility [Wacziarg and Welch (2008)].

Regarding the political shocks, the confidence interval of the APE of negative regime changes widens a bit (the $t$-statistic is 1.90), but the absolute size of the effect remains large. If a country experiences a negative regime change, then the probability of stagnation increases by 21.4 percentage points. As in the logit models, we could not include the interaction term because of a lack of time variation. Although negative regime changes were previously linked to the onset of growth accelerations [Hausmann et al. (2005)], our analysis reveals the more plausible result that they strongly predict stagnation episodes. None of the other political variables, that is, positive regime changes, irregular leader exits, or the Polity score, are robustly related to the incidence of stagnation spells. This finding stands in sharp contrast to the "institutions trump other factors" perspective [e.g., Acemoglu et al. (2001, 2002); Rodrik et al. (2004)], but could be driven by our focus on annual transitions in and out of crises (which are likely to be caused by more proximate factors). 
Undervaluation of the real exchange rate has a moderate and marginally significant effect on the probability of stagnation. A one-standard-deviation change in the undervaluation index reduces the probability of both the onset and the continuation of stagnation by about $4 \%$. We cannot corroborate the results from the logit model that changes in the terms of trade and inequality have any meaningful effect on the probability of stagnation. In addition, wars and civil conflict do not predict stagnation spells, and there is no evidence of an effect of the level of GDP per capita.

Table 5 also reveals that the degree of state dependence is underestimated by both the LPM and FE logit model. If a country experienced stagnation in the previous year, it is 38.9 percentage points more likely to be in stagnation in the current year. Path dependence is thus an important feature of the stagnation process. The models also fit the data reasonably well (pseudo- $R^{2}=0.255$ ), and the fit compares favorably to the onset models used elsewhere [e.g., Hausmann et al. $(2005,2008)]$ - although these goodness of fit criteria are not strictly comparable. Hence, we find that dynamic models (a) allow us to test refined hypotheses about the difference between onset and continuation of stagnation spells and (b) lead to better predictions of when stagnation occurs.

To summarize, the main results are robust to different specifications, assumptions about the unobserved effects, and correlation between the observed variables and unobserved country effects. Most of the preferred specifications identify the lags of inflation and negative regime changes as strong predictors of stagnation episodes. Several models also identify trade openness and financial openness as relevant. The nonlinear models add three important insights. First, there is less evidence of interaction effects with the lagged state than the LPM suggests. The interactions are highly nonlinear and vary significantly across the sample, but only in the case of trade openness do we find convincing evidence that its effect differs depending on whether the country was in stagnation before or not. The evidence of interaction effects between the lagged state and inflation, financial openness, or negative regime changes is weak. Second, the nonlinear models show that the real exchange rate matters for stagnation. An overvalued real exchange rate raises the chances of stagnation, whereas undervaluation reduces it. Third, the level of state dependence is still moderate, but larger than estimated by the linear models with fixed effects.

We also find that lagging all included regressors by one year to ensure that they are at least contemporaneously exogenous results in identifying very different significant factors than if the issue of endogeneity is left unaddressed. For example, Hausmann et al. (2008), who studied the onset of stagnation, found that exports, inflation, wars, and political transitions matter. We do not find significant effects for exports and wars, although we do confirm their results for inflation and negative regime changes.

Interestingly, we cannot confirm two central results of the previous literature. First, we find little evidence that, apart from negative regime changes, institutions generally affect the incidence of stagnation. Consistent with the institutionalist 
literature, we find that poor countries are more prone to stagnation and crisis. However, our analysis contradicts the hypotheses that negative institutional characteristics and internal or external shocks increase the incidence of stagnation. On the contrary, traditional macroeconomic variables predict the incidence of stagnation rather well. Second and contrary to previous research [Rodrik (1999); Hausmann et al. (2008)], our data do not support the finding that changes in real exports or terms of trade affect the probability of stagnation.

\section{CONCLUSION}

This paper provides a dynamic analysis of the incidence of stagnation and examines whether stagnation spells are determined by institutional factors, various shocks, or macroeconomic factors. Building on a recent contribution by Hausmann et al. (2008), we define stagnation spells as episodes in which GDP per capita is below previously achieved levels. We then use fixed-effects linear models, GMM, fixedeffects logit, and dynamic random effects probit to assess the role of institutions, political shocks, and economic factors. In contrast to the previous literature, we explicitly examine the hypothesis that the effects of variables on the onset of stagnation and on the continuation of stagnation may be different.

We identify several factors that explain the incidence of stagnation spells. Adverse regime changes have the single largest effect on the incidence of stagnation, whereas higher inflation increases the chances of being in stagnation. More surprisingly, we find that real exchange rate undervaluation, financial openness, and trade openness help reduce the chances of stagnation. Additionally, we evidence that trade openness primarily protects against falling into stagnation, but does not speed up recovery. For all other variables, there is no evidence of a differential impact on onset versus continuation.

Though traditional macroeconomic factors have the upper hand over institutional factors in our explanations of stagnation, we do not yet know to what extent macroeconomic factors are in turn influenced by underlying institutional characteristics. The use of more differentiated measures and time series for institutions, as well as additional techniques for dealing with endogeneity, might add further insights. This is a promising avenue for future research.

\section{NOTES}

1. For a review of the debates see Bluhm and Szirmai (2012) and for an earlier survey see Aron (2000).

2. The list of empirical studies investigating this issue is long and growing, but the seminal papers are Knack and Keefer (1995), Hall and Jones (1999), Acemoglu et al. (2001, 2002), and Rodrik et al. (2004).

3. More precisely, we measure the growth rate across an expansion as $\bar{g}_{t, t+q}=q^{-1}\left[\ln Y_{i, t+q}-\right.$ $\left.\ln Y_{i t}\right]$, where $q$ is the duration of the expansion. We classify an episode as rapid if $\bar{g}_{t, t+q}>0.05$, and as slow to moderate if $\bar{g}_{t, t+q} \leq 0.05$. 
4. We constructed a similar table classifying countries by their GDP per capita in 1960 rather than at the end of the period. Though there were some differences, the basic finding that rich countries spend less of their time in crisis than poor countries is confirmed.

5. For more details on the construction of the indices see Crombrugghe and Farla (2012). The IPD 2009 is publicly accessible at www.afd.fr/lang/en/home/recherche/bases-ipd.

6. This index is based on the PWT 6.3 and its construction is described in more detail in Table A.1.

7. See Perotti (1996), Deininger and Squire (1998), Barro (2000), and Forbes (2000).

8. Polity IV scores countries on five indices capturing the openness of the political process and the constraints placed on individual actors. We interpret the data as measuring the degree of open institutions with narrow mandates.

9. Further, this model implies that $\operatorname{Corr}\left(\varepsilon_{i}+v_{i t}, \varepsilon_{i}+v_{i s}\right)=\sigma_{\varepsilon}^{2} /\left(\sigma_{\varepsilon}^{2}+\sigma_{v}^{2}\right)$ for any $t \neq s$.

10. The coefficients are scaled differently. The comparison should be made in terms of relative sizes, signs, and significance levels, where appropriate.

\section{REFERENCES}

Acemoglu, Daron, Simon Johnson, and James A. Robinson (2001) The colonial origins of comparative development: An empirical investigation. American Economic Review 91, 13691401.

Acemoglu, Daron, Simon Johnson, and James A. Robinson (2002) Reversal of fortune: Geography and institutions in the making of the modern world income distribution. Quarterly Journal of Economics $117,1231-1294$.

Acemoglu, Daron, Simon Johnson, James A. Robinson, and Yunyong Thaicharoen (2003) Institutional causes, macroeconomic symptoms: Volatility, crises and growth. Journal of Monetary Economics $50,49-123$.

Ai, Chunrong and Edward C. Norton (2003) Interaction terms in logit and probit models. Economics Letters 80, 123-129.

Akay, Alpaslan (2012) Finite-sample comparison of alternative methods for estimating dynamic panel data models. Journal of Applied Econometrics 27, 1189-1204.

Arellano, Manuel and Stephen Bond (1991) Some tests of specification for panel data: Monte Carlo evidence and an application to employment equations. Review of Economic Studies 58, 277 297.

Arellano, Manuel and Olympia Bover (1995) Another look at the instrumental variable estimation of error-components models. Journal of Econometrics 68, 29-51.

Aron, Janine (2000) Growth and institutions: A review of the evidence. World Bank Research Observer $15,99-135$.

Barro, Robert J. (2000) Inequality and growth in a panel of countries. Journal of Economic Growth 5 , $5-32$.

Berg, Andrew, Jonathan D. Ostry, and Jeromin Zettelmeyer (2012) What makes growth sustained? Journal of Development Economics 98, 149-166.

Bluhm, Richard and Adam Szirmai (2012) Institutions and Long-Run Growth Performance: An Analytic Literature Review of the Institutional Determinants of Economic Growth. UNU-MERIT working paper 033, Maastricht Economic and Social Research and Training Centre on Innovation and Technology, United Nations University.

Blundell, Richard and Stephen Bond (1998) Initial conditions and moment restrictions in dynamic panel data models. Journal of Econometrics 87, 115-143.

Bun, Maurice J. G. and Frank Windmeijer (2010) The weak instrument problem of the system GMM estimator in dynamic panel data models. Econometrics Journal 13, 95-126.

Bussière, Matthieu and Marcel Fratzscher (2006) Towards a new early warning system of financial crises. Journal of International Money and Finance 25, 953-973.

Cameron, A. Colin, Jonah B. Gelbach, and Douglas L. Miller (2011) Robust inference with multiway clustering. Journal of Business and Economic Statistics 29, 238-249. 
Cerra, Valerie and Sweta C. Saxena (2008) Growth dynamics: The myth of economic recovery. American Economic Review 98, 439-457.

Chamberlain, Gary (1980) Analysis of covariance with qualitative data. Review of Economic Studies 47, 225-238.

Chamberlain, Gary (1984) Panel data. In Z. Griliches and M. D. Intriligator (eds.), Handbook of Econometrics, Vol. 2, pp. 1247-1318. Amsterdam: Elsevier.

Chinn, Menzie D. and Hiro Ito (2006) What matters for financial development? Capital controls, institutions, and interactions. Journal of Development Economics 81, 163-192.

Crombrugghe, Denis de and Kristine Farla (2012) Preliminary Conclusions on Institutions and Economic Performance. UNU-MERIT working paper 035, Maastricht Economic and Social Research and Training Centre on Innovation and Technology, United Nations University.

Deininger, Klaus and Lyn Squire (1998) New ways of looking at old issues: Inequality and growth. Journal of Development Economics 57, 259-287.

Diebold, Francis X., Glenn Rudebusch, and Daniel Sichel (1993) Further evidence on business-cycle duration dependence. In James H. Stock and Mark W. Watson (eds.) Studies in Business Cycles, Vol. 28, Business Cycles, Indicators, and Forecasting, Chap. 6, pp. 255-285. Chicago: University of Chicago Press.

Engerman, Stanley L. and Kenneth L. Sokoloff (1997) Factor endowments, institutions, and differential growth paths among New World economies. In Stephen Haber (ed.), How Latin America Fell Behind, pp. 260-296. Stanford, CA: Stanford University Press.

Forbes, Kristin J. (2000) A reassessment of the relationship between inequality and growth. American Economic Review 90, 869-887.

Glaeser, Edward L., Rafael La Porta, Florencio Lopez-de Silanes, and Andrei Shleifer (2004) Do institutions cause growth? Journal of Economic Growth 9, 271-303.

Gleditsch, Nils P., Peter Wallensteen, Mikael Eriksson, Margareta Sollenberg, and Håvard Strand (2002) Armed conflict 1946-2001: A new dataset. Journal of Peace Research 39, 615637.

Goemans, Henk E., Kristian S. Gleditsch, and Giacomo Chiozza (2009) Introducing Archigos: A dataset of political leaders. Journal of Peace Research 46, 269-283.

Greene, William H. (2010) Testing hypotheses about interaction terms in nonlinear models. Economics Letters 107, 291-296.

Greene, William H. (2011) Econometric Analysis, 7th ed. Upper Saddle River, NJ: Prentice Hall.

Greif, Avner (2006) Institutions and the Path to the Modern Economy: Lessons from Medieval Trade. Cambridge, UK: Cambridge University Press.

Hall, Robert E. and Charles I. Jones (1999) Why do some countries produce so much more output per worker than others? Quarterly Journal of Economics 114, 83-116.

Hausmann, Ricardo, Lant Pritchett, and Dani Rodrik (2005) Growth accelerations. Journal of Economic Growth 10, 303-329.

Hausmann, Ricardo, Francisco Rodriguez, and Rodrigo Wagner (2008) Growth collapses. In Carmen M. Reinhart, Carlos A. Vegh, and Andres Velasco (eds.), Money, Crises and Transition, pp. 376-428. Cambridge, MA: MIT Press.

Heckman, James J. (1981) The incidental parameters problem and the problem of initial conditions in estimating a discrete time-discrete data stochastic process. In Charles F. Manski and Daniel L. McFadden (eds.), Structural Analysis of Discrete Data With Economic Applications, pp. 179-195. Cambridge, MA: MIT Press.

Heston, Alan, Robert Summers, and Bettina Aten (2009) Penn World Table, Version 6.3. Center for International Comparisons of Production, Income and Prices at the University of Pennsylvania.

Holtz-Eakin, Douglas, Whitney Newey, and Harvey S. Rosen (1988) Estimating vector autoregressions with panel data. Econometrica 56, 1371-1395.

Jerzmanowski, Michał (2006) Empirics of hills, plateaus, mountains and plains: A Markov-switching approach to growth. Journal of Development Economics 81, 357-385. 
Jones, Benjamin F. and Benjamin A. Olken (2008) The anatomy of start-stop growth. Review of Economics and Statistics 90, 582-587.

King, Gary and Langche Zeng (2001) Logistic regression in rare events data. Political Analysis 9, 137-163.

Knack, Stephen and Philip Keefer (1995) Institutions and economic performance: Cross-country tests using alternative institutional measures. Economics and Politics 7, 207-227.

Kuznets, Simon (1955) Economic growth and income inequality. American Economic Review 45, $1-28$.

Marshall, Monty G. and Keith Jaggers (2010) Polity IV Dataset. Center for International Development and Conflict Management, College Park, University of Maryland.

Mundlak, Yair (1978) On the pooling of time series and cross section data. Econometrica 46, 69-85.

Neyman, Jerzy and Elizabeth L. Scott (1948) Consistent estimates based on partially consistent observations. Econometrica 16, 1-32.

Nickell, Stephen (1981) Biases in dynamic models with fixed effects. Econometrica 49, 1417-1426.

North, Douglas C. and Robert P. Thomas (1973) The Rise of the Western World, a New Economic History. Cambridge, UK, and New York: Cambridge University Press.

North, Douglas C., John J. Wallis, and Barry R. Weingast (2009) Violence and Social Orders: A Conceptual Framework for Interpreting Recorded Human History. Cambridge, UK, and New York: Cambridge University Press.

Orme, Chris D. (2001) Two-Step Inference in Dynamic Non-linear Panel Data Models. Mimeo, School of Economic Studies, University of Manchester.

Perotti, Roberto (1996) Growth, income distribution, and democracy: What the data say. Journal of Economic Growth 1, 149-187.

Pritchett, Lant (1998) Patterns of Economic Growth: Hills, Plateaus, Mountains, and Plains. Policy research working paper 1947, World Bank.

Rabe-Hesketh, Sophia and Anders Skrondal (2013) Avoiding biased versions of Wooldridge's simple solution to the initial conditions problem. Economics Letters 120, 346-349.

Reddy, Sanjay and Camelia Minoiu (2009) Real income stagnation of countries 1960-2001. Journal of Development Studies 45, 1-23.

Rodrik, Dani (1999) Where did all the growth go? External shocks, social conflict, and growth collapses. Journal of Economic Growth 4, 385-412.

Rodrik, Dani (2000) Institutions for high-quality growth: What they are and how to acquire them. Studies in Comparative International Development (SCID) 35, 3-31.

Rodrik, Dani (2008) The real exchange rate and economic growth. Brookings Papers on Economic Activity 39(2), 365-412.

Rodrik, Dani, Arvind Subramanian, and Francesco Trebbi (2004) Institutions rule: The primacy of institutions over geography and integration in economic development. Journal of Economic Growth 9, 131-165.

Roodman, David (2009) A note on the theme of too many instruments. Oxford Bulletin of Economics and Statistics 71, 135-158.

Sachs, Jeffrey D. and Andrew Warner (1995) Economic reform and the process of global integration. Brookings Papers on Economic Activity 26(1), 1-118.

Solt, Frederick (2009) Standardizing the world income inequality database. Social Science Quarterly 90, 231-242. SWIID Version 3.0, July 2010.

Wacziarg, Romain and Karen H. Welch (2008) Trade liberalization and growth: New evidence. World Bank Economic Review 22, 187-231.

Windmeijer, Frank (2005) A finite sample correction for the variance of linear efficient two-step GMM estimators. Journal of Econometrics 126, 25-51.

Wooldridge, Jeffrey M. (2005) Simple solutions to the initial conditions problem in dynamic, nonlinear panel data models with unobserved heterogeneity. Journal of Applied Econometrics 20, 39-54.

Wooldridge, Jeffrey M. (2010) Econometric Analysis of Cross Section and Panel Data, 2nd ed. Cambridge, MA: MIT Press. 


\section{APPENDIX A: VARIABLES AND DATA SOURCES}

TABLE A.1. Independent variables, description, construction, and sources

\begin{tabular}{|c|c|c|c|}
\hline Name & Description & Construction & Data source \\
\hline $\log \operatorname{GDPC}_{(t-1)}$ & $\begin{array}{l}\text { Logarithm of GDP } \\
\text { per capita }\end{array}$ & $\ln \left(R G D P C H_{i, t-1}\right)$ & PWT 6.3 \\
\hline Inflation $_{(t-1)}$ & $\begin{array}{l}\text { Change in consumer } \\
\text { prices }\end{array}$ & $100 \times \ln \left(1+\left[g C P I_{i, t-1}\right]\right)$ & IFS \& $\mathrm{WDI}^{\mathrm{a}}$ \\
\hline$\Delta \operatorname{ToT}_{(t-1)}$ & $\begin{array}{l}\text { Change in terms of } \\
\text { trade }\end{array}$ & $\ln \left(T O T_{i, t-1}\right)-\ln \left(T O T_{i, t-2}\right)$ & WDI \& IFS ${ }^{b}$ \\
\hline$\Delta$ Real Exports $(t-1)$ & $\begin{array}{l}\text { Change in exports } \\
\text { volumes }\end{array}$ & $\ln \left(E X P_{i, t-1}\right)-\ln \left(E X P_{i, t-2}\right)$ & WDI \& IFS ${ }^{c}$ \\
\hline $\operatorname{RER}_{\operatorname{Value}_{(t-1)}}$ & $\begin{array}{l}\text { Real exchange rate } \\
\text { valuation }\end{array}$ & See note ${ }^{d}$ & PWT 6.3 \\
\hline Fin. Openness $s_{(t-1)}$ & $\begin{array}{l}\text { Capital account } \\
\text { openness }\end{array}$ & $\mathrm{KAOPEN}_{i, t-1}$ & Chinn-Ito '09 \\
\hline Trade Openness $_{(t-1)}$ & $\begin{array}{l}\text { Trade liberalization } \\
\text { measure }\end{array}$ & 1 if open in $t-1$ & W-W'08 \\
\hline Inequality $_{(t-1)}$ & $\begin{array}{l}\text { Gini coefficient for } \\
\text { income }\end{array}$ & $\mathrm{GINI}_{i, t-1}$ & Solt '09 \\
\hline $\operatorname{Polity} 2_{(t-1)}$ & $\begin{array}{l}\text { Revised combined } \\
\text { polity score }\end{array}$ & DEMOC $_{i, t-1}-$ AUTOC $_{i, t-1}$ & Polity IV \\
\hline Regchange $+_{(t-1)}$ & $\begin{array}{l}\text { Positive regime } \\
\text { change }\end{array}$ & Based on REGTRANS $_{i, t-1}{ }^{\mathrm{e}}$ & Polity IV \\
\hline Regchange $-{ }_{(t-1)}$ & $\begin{array}{l}\text { Negative regime } \\
\text { change }\end{array}$ & Based on REGTRANS ${ }_{i, t-1}^{\mathrm{e}}$ & Polity IV \\
\hline 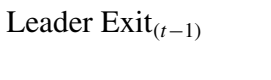 & $\begin{array}{l}\text { Irregular exit of } \\
\text { leader }\end{array}$ & 1 if $\operatorname{EXIT}_{i, t-1} \neq 1^{\mathrm{g}}$ & Archigos 2.9 \\
\hline
\end{tabular}


TABLE A.1. Continued

\begin{tabular}{lclc}
\hline Name & Description & Construction $^{\text {Data source }}$ \\
\hline War/Conflict $_{(t-1)}$ & $\begin{array}{c}\text { Conflicts }(\geq 1000 \\
\text { deaths })\end{array}$ & See note $^{\mathrm{f}}$ & UCDP/PRIO \\
\hline
\end{tabular}

\footnotetext{
${ }^{a}$ We use the IFS series (CPI y-o-y \%-change based on line 64) as a benchmark and append it with the WDI series in 59 cases where the former has missing data.

${ }^{b}$ We use the WDI series as a benchmark (which comprises UNCTAD and IFS data) and append it with the export volume index from the IFS for missing years/countries.

${ }^{c}$ From the WDI 2011, we use the series "net barter terms of trade," and from the IFS, we derive the equivalent net barter terms of trade by dividing the unit value of exports (line 74) by the unit value of imports (line 75) and multiplying the result by 100 . We then append the WDI series of growth rates with the growth rates from the IFS series whenever the former has missing information.

${ }^{d}$ Rodrik (2008) proposes a simple way to calculate an index of "real" exchange rate (RER) overvaluation based only on the Penn World Tables. The method involves three steps: (1) Compute the PPP-adjusted exchange rate: $\ln \left(\mathrm{RER}_{\mathrm{it}}\right)=\ln \left(\mathrm{XRAT}_{\mathrm{it}} / \mathrm{PPP}_{\mathrm{it}}\right)$. (2) Estimate the Balassa-Samuelson effect: $\ln \left(\mathrm{RER}_{\mathrm{it}}\right)=\alpha+\beta \ln \left(\mathrm{RGDPCH}_{\mathrm{it}}\right)+\gamma_{\mathrm{t}}+\mathrm{u}_{\mathrm{it}}$. (3) Take the difference between the actual RER and the predicted RER from (2), hence, $\operatorname{RER}_{\text {Value }}^{(i, t-1)}=\ln \left(\operatorname{RER}_{(\mathrm{i}, \mathrm{t}-1}\right)-\ln \left(\widehat{\mathrm{RER}_{\mathrm{i}, \mathrm{t}-1}}\right)$.

${ }^{e}$ We use the Polity IV variable REGTRANS to identify regime changes in either direction based on a minimum 3-point change in a country's democracy or autocracy score. We exclude the code 0 for "minor changes," which denotes any change in the democracy or autocracy scores. Further, we do not code -77 for "interregna," -66 for (foreign) "interruptions," and -88 for regime "transitions" as negative regime changes to avoid collinearity with the leader exit and war/conflict dummies.

${ }^{f}$ This dummy is constructed based on the UCDP/PRIO Armed Conflict Dataset v.4-2011, 1946-2010. We first converted the conflict-year database into country-year format and then coded the intensity levels for the highest intensity conflict in any given country-year. The dummy is unity if the intensity level of the conflict was coded as 2 in $t-1$ and the country was listed as a location of the conflict.

${ }^{g}$ The Archigos 2.9 time-series database records entries, tenure, and exits of country leaders and the conditions on which they entered and exited. In some instances there are multiple observations per country-year; in such an event we code an irregular exit if any one observation within that year is identified as "irregular." Irregular exit refers to leaders who died in office, committed suicide, or left office because of ill health, other irregular means, or deposition by another state.
}

\section{APPENDIX B: AVERAGE PARTIAL EFFECTS}

Wooldridge (2005) shows that in the dynamic random effects probit model, a consistent and $\sqrt{N}$-asymptotically normal estimator of the APEs of time-varying variables is available. However, the APEs of time-invariant covariates are not identified. Using the same assumptions as in Section 5.2, we can write the conditional expectation over the distribution of $\mu_{i}$ as

$$
\mathrm{E}\left[\Phi\left(\alpha y_{i, t-1}+\mathbf{x}_{i t}^{\prime} \boldsymbol{\beta}+\mu_{i}\right)\right]=\mathrm{E}\left[\Phi\left(\alpha y_{i, t-1}+\mathbf{x}_{i t}^{\prime} \boldsymbol{\beta}+\eta_{0}+\eta_{1} y_{i 1}+\overline{\mathbf{x}}_{i}^{\prime} \boldsymbol{\eta}_{2}+\varepsilon_{i}\right)\right]
$$

where $\mathbf{x}_{i t}$ denotes time-varying regressors, $\overline{\mathbf{x}}_{i}$ their time-averages, and $\varepsilon_{i}=\mu_{i}-\eta_{0}-$ $\eta_{1} y_{i 1}-\overline{\mathbf{x}}_{i}^{\prime} \boldsymbol{\eta}_{2}$. The expectation runs over the distribution of $\left(y_{i 1}, \overline{\mathbf{x}}_{i}, \varepsilon_{i}\right)$. 
Following Wooldridge (2005), we can get rid of the unobserved effects by applying the law of iterated expectations and defining the average structural function (ASF):

$$
\begin{aligned}
\operatorname{ASF}\left(\mathbf{x}_{i t}, y_{i, t-1}\right) & =\mathrm{E}\left[\mathrm{E}\left[\Phi\left(\alpha y_{i, t-1}+\mathbf{x}_{i t}^{\prime} \boldsymbol{\beta}+\eta_{0}+\eta_{1} y_{i 1}+\overline{\mathbf{x}}_{i}^{\prime} \boldsymbol{\eta}_{2}+\varepsilon_{i}\right) \mid y_{i 1}, \overline{\mathbf{x}}_{i}\right]\right] \\
& =\mathrm{E}\left[\Phi\left[\left(\alpha y_{i, t-1}+\mathbf{x}_{i t}^{\prime} \boldsymbol{\beta}+\eta_{0}+\eta_{1} y_{i 1}+\overline{\mathbf{x}}_{i}^{\prime} \boldsymbol{\eta}_{2}\right) \times\left(1+\sigma_{\varepsilon}^{2}\right)^{-1 / 2}\right]\right] \\
& =\mathrm{E}\left[\Phi\left(\alpha_{\varepsilon} y_{i, t-1}+\mathbf{x}_{i t}^{\prime} \boldsymbol{\beta}_{\varepsilon}+\eta_{\varepsilon, 0}+\eta_{\varepsilon, 1} y_{i 1}+\overline{\mathbf{x}}_{i}^{\prime} \boldsymbol{\eta}_{\varepsilon, 2}\right)\right] .
\end{aligned}
$$

Assuming that $\varepsilon_{i} \sim$ i.i.d. $N\left(0, \sigma_{\varepsilon}^{2}\right)$ and $\varepsilon_{i} \perp\left(y_{i 1}, \overline{\mathbf{x}}_{i}\right)$, the scaled parameters in (B.4) are what standard random effects probit estimates. The panel-level likelihood based on the density of $\left(y_{i 1}, \ldots, y_{i T_{i}}\right)$ given $\left(y_{i 1}, \overline{\mathbf{x}}_{i}\right)$ can be written as

$$
\mathcal{L}_{i}=\int_{\mathbb{R}}\left\{\prod_{t=2}^{T_{i}} \Phi\left[q_{i t}\left(\alpha y_{i, t-1}+\mathbf{x}_{i t}^{\prime} \boldsymbol{\beta}+\eta_{0}+\eta_{1} y_{i 1}+\overline{\mathbf{x}}_{i}^{\prime} \boldsymbol{\eta}_{2}+\varepsilon_{i}\right)\right]\right\} \sigma_{\varepsilon}^{-1} \phi\left(\varepsilon_{i} / \sigma_{\varepsilon}\right) \mathrm{d} \varepsilon_{i},
$$

where $q_{i t}=\left(2 y_{i t}-1\right)$ and $\phi(\cdot)$ is the standard normal pdf. The model log-likelihood is $\ln \mathcal{L}=\sum_{i=1}^{N} \ln \mathcal{L}_{i}$.

The scaled parameters also show up directly in the average structural function (ASF). A consistent estimator of the ASF is the simple average across all observations. The derivative of the ASF with respect to a continuous time-varying regressor, the finite difference for a binary regressor, or a mix thereof, is equivalent to the APE of that variable. This approach can easily be extended to include interactions with the lagged state and other nonlinearities. Wooldridge's device to get to the APEs is to always average across the distribution of $\left(y_{i 1}, \overline{\mathbf{x}}_{i}\right)$ first and then to specify the derivatives/differences. For example, the APE of a continuous time-varying variable (without an interaction) in $\mathbf{x}_{i t}$ is

$$
\begin{aligned}
& \operatorname{APE}\left(\beta_{k}\right)=\beta_{\varepsilon, k} \\
& \quad \times\left[\frac{1}{N(\bar{T}-1)} \sum_{i=1}^{N} \sum_{t=2}^{T_{i}} \phi\left(\alpha_{\varepsilon} y_{i, t-1}+\mathbf{x}_{i t}^{\prime} \boldsymbol{\beta}_{\varepsilon}+\eta_{\varepsilon, 0}+\eta_{\varepsilon, 1} y_{i 1}+\overline{\mathbf{x}}_{i}^{\prime} \boldsymbol{\eta}_{\varepsilon, 2}\right)\right],
\end{aligned}
$$

where we also average over time to obtain a single scale factor. It is straightforward to apply the results of Section 5.2 to the APEs of the interaction terms. 